\title{
Molecular interactions at the bovine embryo-endometrial epithelium interface
}

\author{
Mariana Sponchiado ${ }^{1,2,3}$, Waleed F A Marei®1,4 ${ }^{1,}$ Gerrit T S Beemster ${ }^{5}$, Peter E J Bols ${ }^{1}$, \\ Mario Binelli ${ }^{2,3}$ and Jo L M R Leroy ${ }^{1}$ \\ ${ }^{1}$ Department of Veterinary Sciences, Gamete Research Centre, University of Antwerp, Wilrijk, Belgium, ${ }^{2}$ Department \\ of Animal Reproduction, School of Veterinary Medicine and Animal Science, University of São Paulo, Pirassununga, \\ São Paulo, Brazil, ${ }^{3}$ Department of Animal Sciences, University of Florida, Gainesville, Florida, USA, ${ }^{4}$ Department of \\ Theriogenology, Faculty of Veterinary Medicine, Cairo University, Giza, Egypt and ${ }^{5}$ Department of Biology, \\ Laboratory for Integrated Plant Physiology Research (IMPRES), University of Antwerp, Antwerp, Belgium
}

Correspondence should be addressed to J L M R Leroy; Email: jo.leroy@uantwerpen.be

\begin{abstract}
In cattle, pre-implantation embryo development occurs within the confinement of the uterine lumen. Current understanding of the bi-lateral molecular interactions between embryo and endometrium that are required for a successful pregnancy is limited. We hypothesized that the nature and intensity of reciprocal embryo-endometrium interactions depend on the extent of their physical proximity. Bovine endometrial epithelial cells (bEECs) and morulae were co-cultured in juxtacrine (Contact+) or non-juxtacrine (Contact-) apposition. Co-culture with bEECs improved blastocyst rates on day 7.5, regardless of juxtaposition. Contact+ regulated transcription of 1797 endometrial genes vs only 230 in the Contact-group compared to their control (no embryos) counterparts. A subset of 50 overlapping differentially expressed genes (DEGs) defined embryo-induced effects on bEEC transcriptome irrespective of juxtaposition. Functional analysis revealed pathways associated with interferon signaling and prostanoid biosynthesis. A total of 175 genes displayed a graded expression level depending on Contact+ or Contact-. These genes were involved in interferon-related and antigen presentation pathways. Biological processes enriched exclusively in Contact+ included regulation of cell cycle and sex-steroid biosynthesis. We speculate that, in vivo, embryonic signals fine-tune the function of surrounding cells to ultimately maximize pregnancy success.

Reproduction (2020) 160 887-903
\end{abstract}

\section{Introduction}

The endometrial epithelium is the point of contact between the maternal tissues and the embryo in utero. Tightly coordinated cellular and molecular interactions between the competent embryo and the receptive endometrium need to be established to safeguard the pregnancy in eutherian mammals. Disturbances in this complex communication result in early embryonic losses and, therefore, subfertility. This is of special importance in cattle, since up to $40 \%$ of pregnancies fail within the first three weeks of pregnancy (Diskin et al. 2011, 2016).

The embryo-maternal interaction involves dynamic processes precisely coordinated by both the maternal and the embryonic units. In the cow, it is expected that the developing embryo starts to interact with the endometrium as soon as day 5 post-fertilization when the zona pellucida-enclosed morula enters the uterus (Guillomot 1995). The embryo in utero is tightly surrounded by the endometrial luminal epithelium (Wolf et al. 2003); however, until day 20, there is no anatomical union between the conceptus (embryo and associated membranes) and the endometrium. Thus, signaling molecules play an important role in establishing the first embryo-maternal communication. The actions of those molecules can be directed from the embryo toward the maternal tissue, and vice-versa, in a paracrine (i.e. molecules from one cell affect cells in its close proximity to it) or juxtacrine fashion (i.e. molecules from one cell affect cells in physical contact with it). One well-known example of paracrine signaling is the embryo-produced Interferon-tau (IFNT), which is released into the uterine lumen and acts in the endometrium to abrogate the luteolytic cascade (Bazer et al. 1997). Alternatively, juxtacrine signaling could be triggered by cell-cell and cell-matrix interactions, as for example mucins from the endometrium that prevent embryonic attachment (Thathiah \& Carson 2002).

Embryos can thrive successfully until the blastocyst stage in vitro, independent of exposure to the maternal reproductive tract. However, it is clear that the maternal genital tract, including the uterus itself, exerts 
considerable control over the ability of an embryo to develop. For instance, several studies have demonstrated that in vivo cultured embryos differ from their in vitro produced counterparts in terms of developmental competence, morphology, metabolism, gene expression profile, and cryotolerance (reviewed by Rizos et al. 2017). Moreover, exposure to the uterine environment at the post-hatching stage is a prerequisite for embryo elongation in the cow, given that elongation of bovine conceptuses does not occur in vitro (Brandao et al. 2004).

The uterus is a hormonally regulated organ. Ovarian steroids (i.e. estradiol and progesterone, from preovulatory follicles and corpus luteum) exert classical endocrine control of morphological and functional changes in the endometrium that affect embryo development and pregnancy success (Carter et al. 2008, Forde et al. 2009, Mesquita et al. 2015). In contrast, programming of endometrial function exerted by the embryo has not been interrogated to the same extent. In that regard, the endometrium senses the embryo quality (Macklon \& Brosens 2014). For example, the bovine endometrial transcriptome changes when exposed to in vitro- vs in vivo-produced embryos (Mansouri-Attia et al. 2009), and when exposed to standard in vitroproduced vs cloned embryos (Bauersachs et al. 2009). We have reported earlier that the in vivo endometrial transcriptome (Sponchiado et al. 2017) and uterine luminal metabolome (Sponchiado et al. 2019) respond locally to a pre-hatching embryo, as early as day 7 after conception. Other in vitro studies have shown that early embryos modulate the abundance of specific transcripts in endometrial epithelial cells (Talukder et al. 2017, Gómez et al. 2018) and endometrial explants (Passaro et al. 2018). Specific pathways modulated by the embryo include transcripts for interferonstimulated genes (ISGs) and prostaglandin metabolism (Sponchiado et al. 2017). The question still remains whether the endometrial epithelial responses depend on a direct physical proximity between the embryo and the endometrial cells and thus whether the juxtacrine (i.e. physical contact) differs from the non-juxtacrine fashion. We hypothesized that nature and intensity of embryo-induced changes on endometrial transcriptome depend on physical contact between the embryos and the endometrium. Therefore, we aimed to interrogate the embryo-maternal interface for embryo-induced changes in the transcriptome of endometrial epithelial cells. Secondly, we aimed to investigate the impact and the specificity of endometrial cells on morula developmental capacity to the blastocyst stage. We used a co-culture system of embryos and bovine endometrial epithelial cells (bEECs) to elucidate basic cellular mechanisms involved in the early embryo-maternal interaction and their reciprocal effects.

\section{Materials and methods}

\section{Overview of experimental model}

To investigate our research hypotheses, we established a bEECembryo co-culture as a model to investigate the early embryomaternal interactions in vitro. bEEC isolation and culture procedures are described in the Isolation and culture of bovine endometrial epithelial cells section. For validation purposes, and before starting the co-culture experiments, we characterized the bEECs regarding the expression of cell line-specific markers. In the first experiment, bEECs were juxtapositioned to morulae for 48 h, whereas non-juxtacrine condition was accomplished by using a transwell insert. Control groups of bEECs in the absence of embryos and embryos in the absence of bEECs were included. The importance of physical proximity between embryos and endometrial cells was investigated in terms of morula developmental capacity and bEEC transcriptome profiles. In the second experiment, conditioned media from bEECs and mice fibroblasts were used to test the specificity of the endometrial cell's supportive capacity on embryo development from the morula-to-blastocyst stage. An overview of the experimental procedures is given in Fig. 1.

\section{Experiment 1}

In Experiment 1, we aimed to compare the effects of juxtaposition vs non-juxtaposition between embryos and endometrial epithelial cells on bEEC transcriptome and morula developmental capacity. Embryos were co-cultured with bEEC monolayers from day 5.5 p.f. (post-fertilization; morulae) until day 7.5 p.f. (blastocysts). The start of exposure of the endometrial cells to embryos (i.e. day 5.5 p.f.) coincides with the embryo's arrival into the uterus in vivo in the cow (Bazer et al. 1991). In order to maximize the embryo-bEEC physical contact zone and the stimulus promoted by the early embryo, multiple embryos were co-cultured with the bEEC monolayers. In addition, by using pools of 15 embryos per well, differential effects caused by variation between individual embryos were avoided. Juxtacrine interaction was accomplished by placing 15 embryos directly on top of bEEC monolayers. Non-juxtacrine interaction was accomplished by placing 15 embryos in a 96-well cell culture insert (ClearView, IncuCyte $\AA$, USA). The insert membrane (8.0 $\mu \mathrm{m}$ pore size) prevented the direct physical contact between embryos and the endometrial monolayer. The distance between the basal plate and the insert is $1.425 \mathrm{~mm}$. More technical details can be found at the supplier's homepage (https://www. essenbioscience.com/en/products/reagents-consumables/ incucyte-clearview-96-well-cell-migration-plate/).

In vitro produced, day 5.5 morulae were selected under the stereomicroscope and transferred in groups of $15 \pm 1$ to a 96-well plate (ClearView, IncuCyte $($ ) containing $90 \%$ confluent, untreated bEEC monolayers according to the treatments: (i) Control Embryos: morulae without bEECs; (ii) Contact+: morulae juxtapositioned to bEEC monolayers; (iii) Contact-: morulae placed on cell culture transwells, without contact with bEECs; or (iv) Control bEEC: bEECs in the absence of embryos. In each replicate, all experimental 

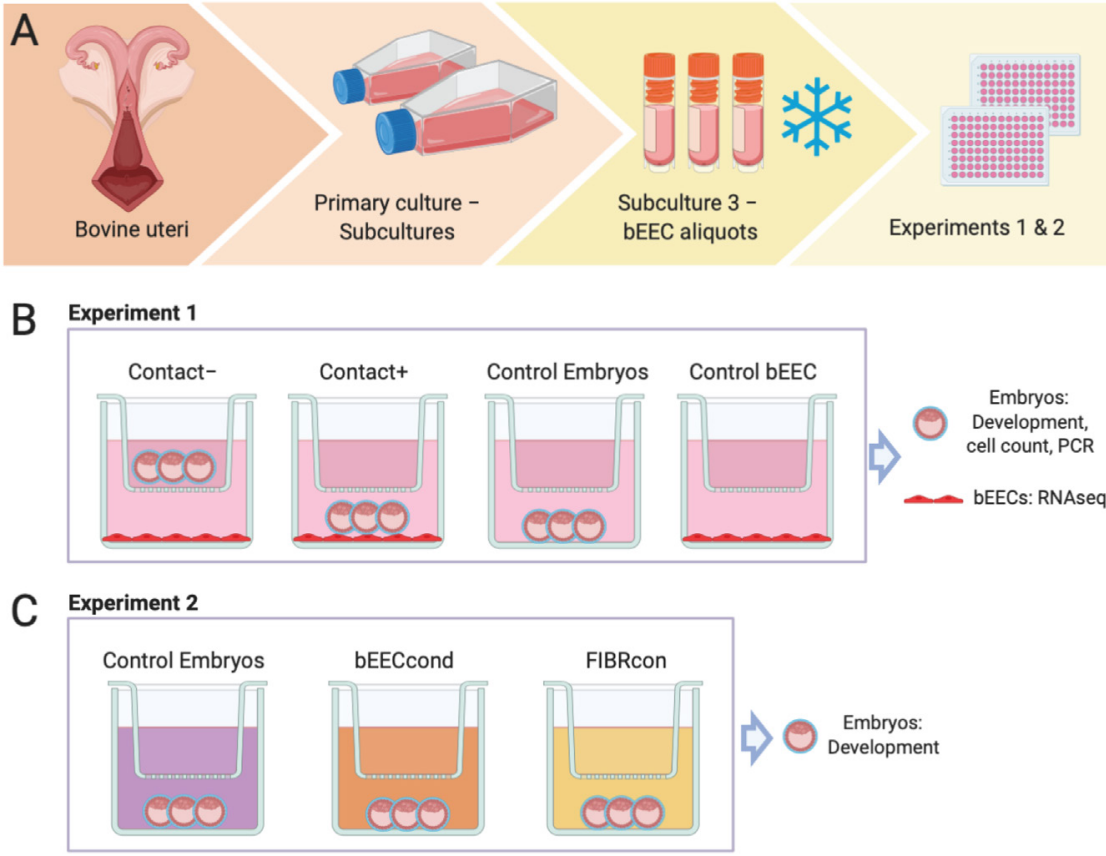

Figure 1 Schematic overview of the experimental model. (A) Bovine endometrial epithelial cells (bEECs) were isolated from uteri ex vivo, pooled, and used for the primary culture. Cells were subcultured until passage 2, when bEECs were cryopreserved. Subculture 3 - bEECs were thawed as needed and assigned to co-culture experiments with embryos (Experiment $1 ; \mathrm{B}$ ), or to generate bEEC conditioned medium (Experiment 2; C). In all replicates, aliquots containing cells originated from the same batch were applied. For means of characterization, cells from each passage were simultaneously cultured in 24-well plates for further PCR analyses. Created with BioRender (https://biorender.com/). conditions were conducted in a single 96-well and received transwells. The experiment was performed in six replicates, with two to four wells of each treatment per replicate. Embryos were transferred using mouth-controlled, fine pore glass capillaries to minimize the volume of media transferred to the wells. Embryos-bEECs co-cultures (for all the experimental conditions) were conducted in $150 \mu \mathrm{L}$ of synthetic oviductal fluid (SOF) medium supplemented with $5 \%$ of fetal bovine serum (FBS), in humidified atmosphere of $5 \% \mathrm{CO}_{2}$ at $38.5^{\circ} \mathrm{C}$. After $48 \mathrm{~h}$ of co-culture, embryos and bEEC monolayers were evaluated and processed as described subsequently.

\section{Sample evaluation and processing}

On day 7.5 p.f., embryo developmental stages were recorded and expressed as a proportion of total number of morulae assigned initially to the treatments. All morphological assessments were conducted using an inverted Olympus CKX41 microscope (Olympus, Belgium). Day 7.5 p.f. blastocysts were either fixed in paraformaldehyde for immunostaining or snap frozen. Embryos were fixed in buffered $4 \%$ paraformaldehyde for $30 \mathrm{~min}$ at room temperature, and stored in PBS-PVP $1 \%$ at $4{ }^{\circ} \mathrm{C}$. Groups of 5 embryos were washed in PBS-PVP 1\%, snap frozen and stored at $-80^{\circ} \mathrm{C}$. bEEC monolayers were washed with pre-warmed PBS $\left(\mathrm{Ca}^{2+} \mathrm{Mg}^{2+}\right.$ free $)$ to remove serum traces and detached cells, and then dispersed with pre-warmed TrypLE Express (Thermo Fisher Scientific) for $6 \mathrm{~min}$ at $38.5^{\circ} \mathrm{C}$. The reaction was inactivated by dilution by adding PBS $\left(\mathrm{Ca}^{2+} \mathrm{Mg}^{2+}\right.$ free). bEECs were transferred and centrifuged at $200 \mathrm{~g}$ for $10 \mathrm{~min}$ at $24^{\circ} \mathrm{C}$. Cell pellets were snap frozen and stored at $-80^{\circ} \mathrm{C}$ for further processing.

\section{Experiment 2}

In this experiment, we aimed to identify potential non-specific embryo supportive effects elicited by bEECs on embryo development. By using conditioned medium from mice fibroblasts, we tested whether heterologous, unspecific feeder cells could similarly support embryo development. Moreover, by using a medium conditioned by bEECs, we investigated the potential non-specific effect of a reduced $\mathrm{O}_{2}$ tension caused by the bEEC monolayer that may had favored embryo development in experiment 1. Therefore, in vitro produced day 5.5 morulae/ early blastocysts were cultured in fresh conditioned medium from bEECs or mice fibroblasts as described subsequently. Experiment was performed in five replicates, with two to five wells of each condition included in each replicate.

\section{Conditioned medium preparation and treatments}

Spent or control medium from six wells were pooled and centrifuged at $200 \mathrm{~g}$ for $5 \mathrm{~min}$ at $24^{\circ} \mathrm{C}$ to remove cells/debris. After 30 min of equilibration in the incubator, $150 \mu \mathrm{L}$ of medium were distributed in a 96-well plate (ClearView, IncuCyte $($ ). Subsequently, groups of $15 \pm 1$ day 5.5 morulae were assigned to the following treatments: (i) Control Embryos: Culture medium (SOF + 5\% FBS); (ii) bEECcond: bEEC-conditioned SOF + 5\% FBS medium; or (iii) FIBRcond: fibroblast-conditioned SOF $+5 \%$ FBS medium. Embryos were transferred using mouth-controlled fine pore glass capillaries to minimize the volume of media transferred to the wells. Embryos were cultured in humidified atmosphere of $5 \% \mathrm{CO}_{2}$ at $38.5^{\circ} \mathrm{C}$ from day 5.5 until day 7.5 p.f. The medium was replaced with freshly prepared conditioned (or control) medium in $50 \%$ of the volume after $24 \mathrm{~h}$. On day 7.5 , embryos were visually scored according to their developmental stages using an inverted Olympus CKX41 microscope.

\section{Isolation and culture of bovine endometrial epithelial cells (bEECs)}

Chemicals used to prepare cell and embryo culture media were purchased from Life Technologies (Thermo Fisher Scientific) or from Sigma Chemical Co., unless otherwise stated. 


\section{Cell collection and primary culture}

Reproductive tracts at early luteal phase (i.e. containing a corpus haemorrhagicum; Ireland et al. 1980) of the estrous cycle were collected from Bos taurus beef cows at a local slaughterhouse, inspected for the absence of reproductive abnormalities or disorders, and transported to the laboratory at $30^{\circ} \mathrm{C}$. Four uteri were trimmed free of surrounding tissues and externally decontaminated with $70 \%$ ethanol. The uterine horn ipsilateral to the ovary containing the corpus haemorrhagicum was opened longitudinally at the mesometrial insertion and the endometrial luminal surface was carefully scraped with sterile glass slides. Cells collected from the four uteri were pooled in an equilibrated, pre-warmed cell culture medium. The cell culture medium consisted of DMEM/F-12 phenol redfree medium (Product number 11039-021; Gibco, Thermo Fisher Scientific) supplemented with 10\% FBS (Product number F9665; Sigma-Aldrich), 2\% penicillin/streptomycin, and $1 \%$ fungizone. Cells were pelleted at $200 \mathrm{~g}$ for $5 \mathrm{~min}$ at $24^{\circ} \mathrm{C}$, and erythrocytes were subsequently lysed by incubation with a hyper-osmotic lysis buffer ( $1 \mathrm{mM}$ EDTA disodium salt, $150 \mathrm{mM} \mathrm{NH}_{4} \mathrm{CL}$ and $100 \mathrm{mM} \mathrm{NaHCO}$ ) for $1 \mathrm{~min}$. Reaction was neutralized with culture medium and the cell suspension was recentrifuged. After washing twice, $1 \times 10^{6}$ viable cells/ flask were plated in $25 \mathrm{~cm}^{2}$ culture flasks and pre-incubated in a humidified atmosphere of $5 \% \mathrm{CO}_{2}$ at $38.5^{\circ} \mathrm{C}$ for $1 \mathrm{~h} 30 \mathrm{~min}$. The pre-incubation step aimed to remove contaminating nonepithelial cells. The supernatant (containing non-attached, epithelial cells) was transferred toward $25 \mathrm{~cm}^{2}$ culture flasks and maintained in a humidified atmosphere of $5 \% \mathrm{CO}_{2}$ at $38.5^{\circ} \mathrm{C}$. After the adhesion process started, culture medium was changed every $48 \mathrm{~h}$.

\section{Subculture and freezing procedures}

Cells were subcultured when primary monolayers reached $90 \%$ of confluence. Cells were washed with PBS $\left(\mathrm{Ca}^{2+} \mathrm{Mg}^{2+}\right.$ free) and then dispersed using TrypLE Express (Thermo Fisher Scientific) for $6 \mathrm{~min}$. Reaction was inactivated by the addition of culture medium. Cells were pelleted at $200 \mathrm{~g}$ for $5 \mathrm{~min}$ at $24^{\circ} \mathrm{C}$. bEECs were seeded at a density of $2 \times 10^{6}$ viable cells/ flask into $75 \mathrm{~cm}^{2}$ culture flasks and cultured as described for primary culture. Passage one monolayers at 95\% of confluence were dissociated as described previously and plated at a density of $1.5 \times 10^{6}$ viable cells/flask in $75 \mathrm{~cm}^{2}$ culture flasks. bEECs were cultured as described for primary culture. Subconfluent (90\%) monolayers were dispersed as described previously. The resulting cell pellet was diluted in cryopreservation medium (DMEM/F-12 phenol red-free medium supplemented with $15 \%$ FBS and $10 \%$ DMSO) at a concentration of $1 \times 10^{6}$ viable cells $/ \mathrm{mL}$. Cryovials containing bEECs were placed in a freezing container (Nalgene ${ }^{\circledR}$ Cryo, Thermo Fisher Scientific), kept at $-80^{\circ} \mathrm{C}$ overnight, and afterwards stored in liquid nitrogen. Experiments were performed using bEECs at passage three, thawed from the same batch.

\section{bEEC cell line characterization}

bEEC cultures were conducted to evaluate the presence of cytokeratin and vimentin, epithelial and mesenchymal cell markers, respectively, and the abundance of functional key transcripts from primary culture to passage three. For this purpose, cells were seeded into 24-well plates for further trypsinization and retrieval for PCR analysis. For fixation and immunostaining analysis, cells were grown on sterile glass coverslips. Cell cultures were conducted as described previously (see 'Cell collection and primary culture and 'Subculture and freezing procedures' sections). Subconfluent bEEC monolayers grown on coverslips were washed with PBS $\left(\mathrm{Ca}^{2+} \mathrm{Mg}^{2+}\right.$ free), fixed in buffered $4 \%$ paraformaldehyde for $30 \mathrm{~min}$ at room temperature, and stored at $4{ }^{\circ} \mathrm{C}$ for further immunostaining procedures. For PCR analysis, bEECs were trypsinized for $6 \mathrm{~min}$, retrieved and centrifuged at $200 \mathrm{~g}$ for 5 min at $24^{\circ} \mathrm{C}$. Cell pellets were snap frozen and kept at $-80^{\circ} \mathrm{C}$ until RNA isolation.

\section{bEEC assignment to treatments (experiments 1 and 2)}

Vials containing bEECs at passage three were thawed, resuspended in $10 \mathrm{~mL}$ of pre-warmed culture medium, and pelleted at $200 \mathrm{~g}$ for $5 \mathrm{~min}$ at $24^{\circ} \mathrm{C}$. This step aimed to remove residual DMSO from the freezing medium. Cells were resuspended in pre-warmed culture medium and seeded into a $0.1 \%$ gelatin-coated 96-well ClearView Reservoir Plate (IncuCyte®; Sartorius) at a density of $1.5 \times 10^{4}$ cells/well. bEECs were maintained in DMEM/F-12 phenol red-free medium supplemented with $10 \%$ FBS, $2 \%$ penicillin/streptomycin, and $1 \%$ fungizone, in a humidified atmosphere of $5 \% \mathrm{CO}_{2}$ at $38.5^{\circ} \mathrm{C}$. The medium was changed every $48 \mathrm{~h}$. Approximately $90 \mathrm{~h}$ h after plating, monolayers at 90\% confluency were assigned to treatments as described previously for Experiments 1 and 2. In Experiment 2, DMEM/F12-based culture medium of bEEC and mice fibroblast subconfluent monolayers was replaced by SOF medium supplemented with 5\% of FBS. Additional wells containing only SOF $+5 \%$ FBS medium were included. After $24 \mathrm{~h}$, spent or control medium were retrieved and assigned to experimental conditions.

\section{In vitro production of bovine embryos}

Bovine embryos were produced in vitro as described previously (Marei et al. 2019) with minor modifications. Briefly, ovaries were collected at a local slaughterhouse and transferred to our laboratory within 2-3 h of slaughter. Antral follicles with a diameter of $3-8 \mathrm{~mm}$ were aspirated. Immature, unexpanded cumulus-oocytes complexes (COCs) were matured in vitro in groups of $50 \pm 5$ COCs in four-well plates containing maturation medium (500 $\mathrm{L}$ /well) for $24 \mathrm{~h}$ in a humidified atmosphere with $5 \% \mathrm{CO}_{2}$ at $38.5^{\circ} \mathrm{C}$. Groups of $100 \pm 10$ matured COCs were transferred to Fert-TALP medium containing $1 \times 10^{6}$ sperm cells $/ \mathrm{mL}$. For all replicates, frozen bull semen from the same ejaculate with proven in vitro fertility was used following selection of motile spermatozoa by centrifugation on a discontinuous $45-90 \%$ Percoll gradient. COCs were co-incubated with spermatozoa in four-well plates $\left(500 \mu \mathrm{L} /\right.$ well) for $22 \mathrm{~h}$ in a humidified atmosphere of $5 \% \mathrm{CO}_{2}$ at $38.5^{\circ} \mathrm{C}$. Following in vitro fertilization, denuded presumptive zygotes were cultured in groups of $25 \pm 2$ in $75 \mu \mathrm{L}$ of SOF medium supplemented with $5 \%$ FBS. Embryo cultures were 
carried out in 96-well plates under controlled atmosphere of $5 \% \mathrm{CO}_{2}, 5 \% \mathrm{O}_{2}, 90 \% \mathrm{~N}_{2}$ at $38.5^{\circ} \mathrm{C}$ until day 5.5 p.f., when compact and non-compact morulae were selected and assigned to experimental conditions.

\section{Immunofluorescence}

\section{$b E E C$}

Cells were permeabilized with PBS containing 1\% Triton X-100 and $0.05 \%$ Tween-20 for $30 \mathrm{~min}$ at room temperature. After washing, samples were blocked in PBS containing $2 \% \mathrm{w} / \mathrm{v}$ BSA and $0.05 \%$ Tween-20, for $45 \mathrm{~min}$ at room temperature. Cells were then incubated with primary antibodies overnight at $4^{\circ} \mathrm{C}$. Cells were immunostained for an epithelial cell marker (anti-pan Cytokeratin mouse MAB; 1:100 in blocking solution; M3515, Dako), and for a mesenchymal cell marker (anti-Vimentin rabbit polyclonal antibody; 1:100 in blocking solution; ab45939, Abcam). Negative control samples were incubated with an equivalent mixture of normal mouse and rabbit IgGs replacing the primary antibodies. Monolayers were washed and subsequently incubated with the secondary antibodies Texas Red-labeled goat anti-mouse (1:200 in blocking solution; Life Technologies) and FITC-labeled goat anti-rabbit (1:200 in blocking solution; Novex, Life Technologies) for $1 \mathrm{~h}$ at $4^{\circ} \mathrm{C}$. Nuclei were counter-stained with Hoechst $33342(30 \mu \mathrm{g} / \mathrm{mL}$ in PBS-PVP) for $10 \mathrm{~min}$ at room temperature. Thereafter, coverslips were mounted on glass slides in droplets of $1 \%$ DABCO.

\section{Embryos}

Day 7.5 blastocysts $(n=91)$ were differentially immunostained to determine inner cell mass (ICM) and trophectoderm (TE) cell number using an immunofluorescence method adapted from Wydooghe et al. (2011). Briefly, fixed blastocysts were permeabilized in $0.1 \%$ Triton X-100 and $0.05 \%$ Tween-20 in PBS overnight at $4{ }^{\circ} \mathrm{C}$, and incubated in blocking solution (10\% normal goat serum in $0.05 \%$ Tween-20 in PBS) for $2 \mathrm{~h}$ at $4{ }^{\circ} \mathrm{C}$. Blastocysts were incubated overnight at $4{ }^{\circ} \mathrm{C}$ in primary antibody solution containing a 1:1 mixture of mouse anti-caudal type homeobox 2 (CDX2) ready-to-use antibody (BioGenex, San Ramon, USA) in blocking solution, as a marker for TE cells. Negative control embryos were incubated with normal mouse IgG at the same concentration as the primary antibody. Embryos were washed in PBS-PVP 1\% and subsequently incubated with the secondary antibody Texas Red-labeled goat anti-mouse (1:200 in blocking solution; Life Technologies) for $4 \mathrm{~h}$ at $4^{\circ} \mathrm{C}$. Nuclei were counter-stained in Hoechst $33342(30 \mu \mathrm{g} / \mathrm{mL}$ in PBS-PVP $1 \%)$ for $10 \mathrm{~min}$ at room temperature. Blastocysts were mounted onto glass slides in droplets of $1 \%$ DABCO and covered with coverslips.

Cells and embryos were visualized under a fluorescence microscope IX71 (Olympus) equipped with CellSens software using the following three filters: DAPI (excitation/emission: 360-370/420-460 nm), FITC (460-490/520-540 nm) and RITC (510-550/>570 nm). Embryonic cell counting was performed by a blinded investigator.

\section{Total RNA isolation and cDNA synthesis}

\section{bEEC (Experiment 1)}

Total RNA isolation was carried out using PicoPure RNA Isolation Kit (Thermo Fisher). Briefly, bEEC samples were subjected to cell lysis in $500 \mu \mathrm{L}$ of Extraction Buffer for $30 \mathrm{~min}$ at $42^{\circ} \mathrm{C}$. Lysates were loaded into pre-conditioned purification columns and processed as per manufacturer's instructions. Membranes were subjected to on-column DNase (RNaseFree DNase Set; Qiagen) treatment at room temperature for $15 \mathrm{~min}$ according to the standard protocol. After subsequent washing, the membrane-bound RNA was eluted in $16 \mu \mathrm{L}$ of the Elution Buffer provided. Total RNA yield and integrity were assessed using RNA 6000 Nano Lab-chips on a Bioanalyzer 2100 (Agilent Genomics). Absorbance ratios (28S/18S) and RNA integrity values ranged between 2.0-2.6 and 8.5-10.0, respectively. The isolated RNA samples were stored at $-80^{\circ} \mathrm{C}$ until RNA sequencing.

\section{bEEC (cell line characterization)}

Total RNA was isolated using Trizol Reagent (Invitrogen, Thermo Fisher Scientific) in accordance with manufacturer's guidelines with minor modifications. Briefly, samples were lysed in $200 \mu \mathrm{L}$ of Trizol and incubated at room temperature for $5 \mathrm{~min}$. Subsequently, $128 \mu \mathrm{L}$ of chloroform were added and samples were centrifuged at $10,000 \mathrm{~g}$ for $15 \mathrm{~min}$ at $4{ }^{\circ} \mathrm{C}$ for phase separation. The aqueous phase was transferred toward a new microtube and $400 \mu \mathrm{L}$ of isopropanol were added. At this step, samples were stored overnight at $-80^{\circ} \mathrm{C}$ to maximize RNA precipitation. Samples were pelleted at 10,000 $\mathrm{g}$ for 12 min at $4^{\circ} \mathrm{C}$, and washed in $400 \mu \mathrm{L}$ of $75 \%$ ethanol, followed by centrifugation at $10,000 \mathrm{~g}$ for $8 \mathrm{~min}$ at $4^{\circ} \mathrm{C}$. Air-dried RNA pellets were resuspended in $10 \mu \mathrm{L}$ of DEPC water and, subsequently, incubated at $55^{\circ} \mathrm{C}$ for $10 \mathrm{~min}$. Total RNA yield and purity (260/280 nm ratio) were evaluated by NanoDrop (Thermo Fisher Scientific) spectrophotometer analysis. RNA extracts were stored at $-80^{\circ} \mathrm{C}$. Total RNA $(1 \mu \mathrm{g})$ samples were treated with DNase I (Promega) according to the standard protocol. First-strand cDNA was synthesized using random hexamers (High Capacity cDNA RT kit; Invitrogen) and by incubation at $25^{\circ} \mathrm{C}$ for $10 \mathrm{~min}$, followed by incubation at $37^{\circ} \mathrm{C}$ for $2 \mathrm{~h}$ and reverse-transcriptase inactivation at $85^{\circ} \mathrm{C}$ for $5 \mathrm{~min}$. The cDNA was stored at $-20^{\circ} \mathrm{C}$ until PCR analyses.

\section{Embryos (Experiment 1)}

Pools of 15 embryos (developmental stages were distributed equally among samples) were subjected to total RNA isolation using PicoPure RNA Isolation Kit (Thermo Fisher) as described for bEECs. Membrane-bound nucleic acids were subjected to on-column DNase (RNase-Free DNase Set; Qiagen) treatment at room temperature for $15 \mathrm{~min}$ according to the standard protocol. Total RNA yield and purity (260/280 nm ratio) were evaluated by NanoDrop (Thermo Fisher Scientific) spectrophotometer analysis. Total RNA (50 ng) was reverse transcribed using Sensiscript RT kit (Qiagen) according to manufacturer's instructions with minor modifications. The master mix was 
composed by the Sensiscript Reverse Transcriptase and the buffer RT supplied in the kit, supplemented with Recombinant RNasin RNase inhibitor (Promega), Oligo-dT (Promega) and Random (Promega) primers at a final concentration of $1 \mu \mathrm{M}$ and $10 \mu \mathrm{M}$, respectively, and dNTP mix (Promega) at a final concentration of $0.5 \mathrm{mM} /$ each dNTP. Samples were incubated in a thermocycler at $37^{\circ} \mathrm{C}$ for $1 \mathrm{~h}$ and stored at $-20^{\circ} \mathrm{C}$ until PCR analyses.

\section{Real-time PCR}

Relative abundance of transcripts was analyzed by real-time PCR. Transcripts analyzed in bEECs included cell origin markers (KRT18 and VIM), and mRNA associated with endometrial function (ESR1, IFNAR1 and PTGS2). PCR analyses in day-7.5 embryos included a marker for TE cells (CDX2), interferontau (IFNT2), and a gene associated with apoptosis (BAX). Specific pairs of primers were designed based on the Bos taurus GenBank Ref-Seq mRNA. Reactions were carried out in duplicates in 96-well plates using the CFX Connect real-time PCR detection system (Bio-Rad Laboratories). PCR reactions were conducted in a final volume of $16 \mu \mathrm{L}$, consisting of 8 $\mu \mathrm{L}$ of SsoAdvanced Universal SYBR Green supermix (Bio-Rad Laboratories), $0.4 \mu \mathrm{L}$ of forward and reverse primers, and $4 \mu \mathrm{L}$ of cDNA template. Negative control reactions (DEPC-treated water replacing template cDNA) were included in every run. The program consisted of an initial denaturation step at $95^{\circ} \mathrm{C}$ for $15 \mathrm{~s}$, followed by 40 cycles each of $30 \mathrm{~s}$ at $95^{\circ} \mathrm{C}$, annealing at $59-61^{\circ} \mathrm{C}$ for $30 \mathrm{~s}$, and extension at $72^{\circ} \mathrm{C}$ for $20 \mathrm{~s}$. After a final extension step of $72^{\circ} \mathrm{C}$ for $5 \mathrm{~min}$, melting curves were plotted by stepwise increases in the temperature from 50 to $95^{\circ} \mathrm{C}$. The annealing temperature was optimized for each primer assay. Relative abundances were obtained after normalization of the target genes $\mathrm{Cq}$ (Crossing Point) values by the geometric mean of the reference genes $\mathrm{Cq}$ values according to the mathematical model described by Pfaffl (2001). PPIA, GAPDH and ACTB were used as reference genes for bEECs. H2AFZ, GAPDH and $R N 18 S 1$ were used as reference genes for embryos. Primers details are provided in Supplementary Table 1 (see section on supplementary materials given at the end of this article).

\section{RNA sequencing}

Fifteen bEEC samples (Experiment 1; 5/treatment) were selected for transcriptome analysis. Each sample consisted of bEECs retrieved from an individual well. Samples were selected based on specific criteria: (i) samples from the Contact+ and Contact- groups having embryos developed to similar blastocyst rates and stages; and (ii) samples of all three groups pertaining to the same replicates. Blastocyst developmental rates for each sample assigned to RNAseq analysis are given in Supplementary Table 2.

Poly-A containing mRNA molecules were purified from total RNA using oligo(dT)-attached magnetic beads and fragmented into small pieces using divalent cations under elevated temperature. First-strand cDNA was synthetized using random hexamer-primed RT, followed by a second-strand cDNA synthesis using DNA Polymerase I and RNase $\mathrm{H}$. The synthesized cDNA was subjected to end-repair and 3' adenylation. Adapters were ligated to the ends of $3^{\prime}$ adenylated cDNA fragments. cDNA fragments with adapters from previous step were amplified by PCR. The resulting PCR products were purified with Agencourt AMPure XP Beads (Beckman Coulter, Beverly, MA, US), and dissolved in buffer EB. Double stranded PCR products were heat-denatured and circularized by the splint oligo sequence. Single stranded circular DNAs (ssCir DNA) were used for PE100 strand-specific library construction and validation on the Bioanalyzer 2100 (Agilent Genomics). The library was amplified with phi29 and DNA nanoballs (DNBs) were generated with ssCir DNA by rolling circle replication (RCR) to intensify the fluorescent signals during the sequencing process. The DNBs were loaded into the patterned nanoarray and pair-end reads of $100 \mathrm{bp}$ were read on the BGISEQ-500 (Cambridge, MA, US) platform for subsequent data analysis.

The data presented in this publication have been deposited in the Gene Expression Omnibus (GEO) database, https:// www.ncbi.nlm.nih.gov/geo and are accessible through GEO Series Access Number GSE151868.

\section{Statistical analysis and bioinformatics}

Statistical analyses were carried out using SAS 9.4 software. Discrete variables, such as blastocyst rates and the proportion of blastocysts reaching the expanded-stage or beyond were analyzed by PROC GLIMMIX using binomial distribution. Replicates were included as random effects in the model. When the effect of treatment was significant, means across treatments were compared by DIFF adjusted by Tukey-Kramer test. Continuous variables, such as gene expression data, cell counts and ICM:TE ratios were checked for normality of residues and homogeneity of variances by Shapiro-Wilk and Welch's test, respectively. Variables were transformed by log or square root when necessary to fulfill assumptions. Effects of treatments were determined using PROC MIXED by ANOVA considering Type III sums of squares. When significant, means across treatments were compared using DIFF adjusted by Tukey-Kramer test. $P$-value $\leq 0.05$ indicates a significant difference, and $P>0.05$ to $P \leq 0.1$ indicates a tendency. Data are presented as mean \pm S.E.M., unless otherwise indicated.

RNA-sequencing data analysis was performed in Galaxy (https://usegalaxy.org). Quality control was performed by FastQC (version 0.71). Paired reads were mapped to the Bos taurus reference genome (UMD 3.1) using HISAT2 (version 2.1.0), after which the counts per gene model was performed with FeatureCounts (version 1.6.2). Expression values were normalized and global and pairwise statistics were performed using DESeq2 (version 1.18.1) using false discovery rate (FDR)corrected $P$ values.

Canonical pathways of the differentially expressed genes (DEGs) was performed using Core Analyses in Ingenuity ${ }^{\circledR}$ Pathway Analysis (IPA, QIAGEN bioinformatics). A cutoff of DEGs with fold-changes $>1.5$ and adjusted $P$ values $\leq 0.05$ was applied. A detailed description of the IPA analysis is available on the manufacturer's homepage (https://www. qiagenbioinformatics.com/products/features/). Heatmaps were generated with heatmapper software (https://heatmapper.ca) applying average linkage and Sperman rank correlation method for clustering and distance measurements, respectively. 


\section{Results}

\section{Functional characteristics of cultured bovine endometrial epithelial cells}

For validation purposes and before starting the co-culture experiments, we characterized the bEEC cell line regarding the expression of cell-line specific markers. Of note, during primary culture, isolated bEECs attached to the plastic surface of culture dishes and exhibited a mixture of elongated, round and spindle morphologies (data not shown). However, after the first passage, monolayers consisted of a homogeneous population of epithelial-like adherent cells, and that feature remained constant after two subsequent passages.

We compared the abundance of transcripts for cellorigin and functional markers by real-time PCR in bEECs among primary culture and three subsequent passages. Gene expression data showed no changes in the abundance of transcripts for keratin 18 (KRT18) among passages; however, we verified a six-fold increase $(P<0.001$, Fig. $2 \mathrm{~A})$ in the abundance of vimentin $(V I M)$ mRNA from primary culture to passage one, that remained constant until passage 3 . Immunostaining revealed that the bEECs after the first passage co-expressed cytokeratin, a typical cytoplasmic marker for epithelial origin, together with vimentin, a marker of mesenchymal-derived cells (Fig. 2B). Immunofluorescence data also confirmed that expression of VIM mRNA in the cell lysates was not due to contaminating fibroblasts in our cell line but because of a dedifferentiated status of the cells. Abundance of transcripts for estrogen receptor alpha (ESR1), prostaglandin-endoperoxide synthase 2 (PTCS2), and interferon alpha and beta receptor subunit 1 (IFNAR1), however, remained similar among primary culture and the first three passages, suggesting that the endometrial cells conserved these functional characteristics (Fig. 2A).

\section{Effect of co-culture with bEECs on embryo development}

In vitro-produced day-5.5 morulae were cultured for $48 \mathrm{~h}$ in SOF $+5 \%$ FBS medium in the absence of bEEC (Control Embryos), juxtapositioned to subconfluent bEEC monolayers (Contact+), or on transwells, without direct contact with bEECs (Contact-). Co-culture with bEECs significantly increased the proportion of morulae reaching the blastocyst stage on day-7.5, regardless of juxtaposition (Table 1). Additionally, the proportion of blastocysts that reached the expanded, hatching or hatched stages was significantly greater $(P=0.0048)$ or tended $(P=0.0784)$ to be greater in the Contact- and Contact+ groups, respectively, compared to the Control Embryos. Although the average counts of total cells in day 7.5 blastocysts were similar across treatments, there was an increase in the ICM/TE ratio in Contact+ blastocysts (Table 1). This difference in blastomere cell fate, however, did not impact the abundance of CDX2 mRNA between the three culture conditions (Fig. 3). Surprisingly, Contact- embryos presented a four-fold increased abundance of transcripts for IFNT2

A
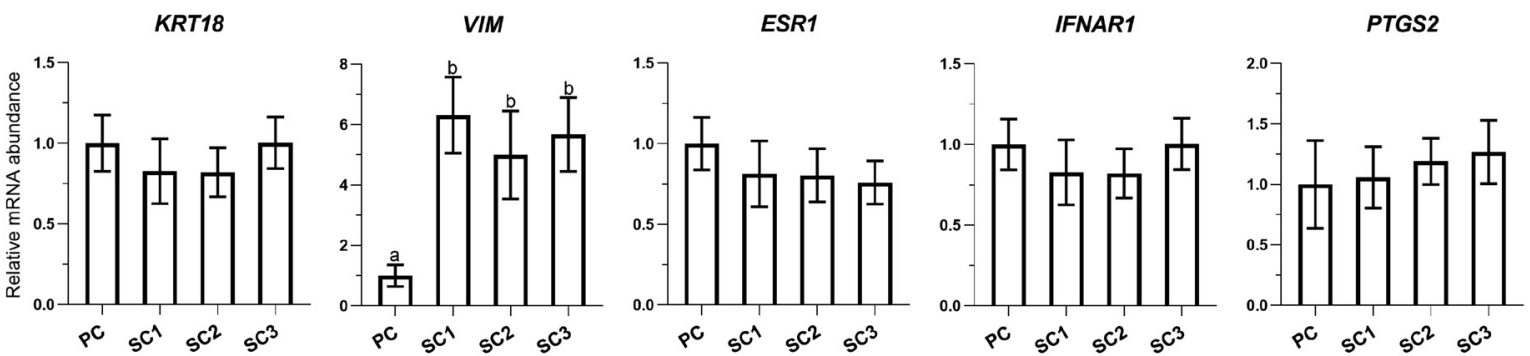

B
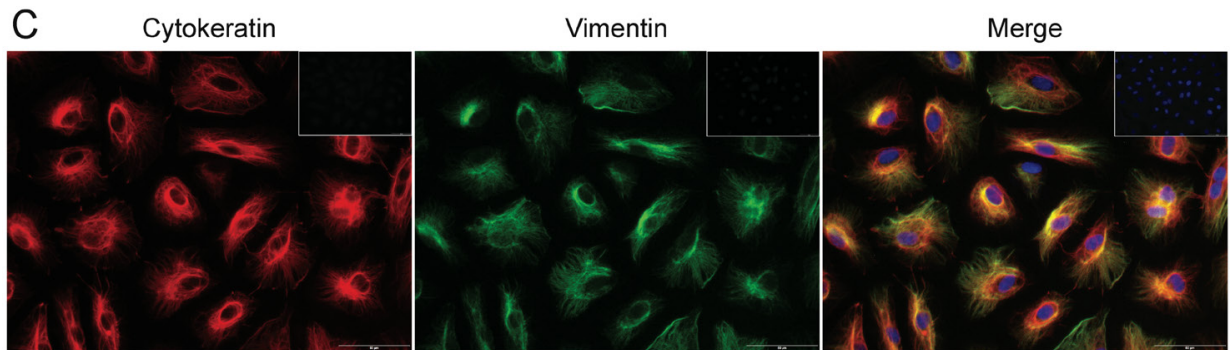

Figure 2 Functional characteristics of cultured bovine endometrial epithelial cells (bEECs). (A) Relative mRNA abundance of keratin 18 (KRT18), vimentin (VIM), estrogen receptor alpha (ESR1), prostaglandin-endoperoxide synthase 2 (PTGS2), and interferon alpha and beta receptor subunit 1 (IFNAR1) in bEECs along primary culture (PC), subculture 1 (SC1), SC2 and SC3. Data are shown as arbitrary units; mean \pm S.E.M. a,bStatistically significant difference in mRNA abundance $(P \leq 0.05, n=8)$. (B) Light microscopy image of a confluent bEEC monolayer $(\times 10$ magnification). (C) Representative image of immunostaining for epithelial (pan cytokeratin, in red) and stromal (vimentin, in green) cell markers. The bEECs were positive for both markers. Nuclei are stained in blue. Scale bar $=50 \mu \mathrm{m}$. Negative controls were incubated with an equivalent mixture of normal mouse and rabbit IgGs instead of primary antibodies (top right inserts). 
Table 1 Effects of co-culture with bovine endometrial epithelial cells (bEEC) on embryo development. On day-5.5 p.f. (post-fertilization), groups of $15 \pm 1$ untreated morulae were cultured in SOF-based medium in the absence of bEEC (Control Embryos), juxtacrine (Contact+) or non-juxtacrine (Contact-) apposition. Of the total oocytes (1970) assigned to in vitro fertilization, 640 (32.5\%) morulae were assigned to treatments.. On day-7.5 p.f., embryonic development was recorded. Blastocysts' total cell count and trophectoderm (TE): Inner Cells Mass (ICM) ratio were assessed by differential immunostaining.

\begin{tabular}{lccc}
\hline \multirow{2}{*}{ Variables } & \multicolumn{3}{c}{ Groups } \\
\cline { 2 - 4 } & Control embryos, $n=14$ wells & Contact+, $n=15$ wells & Contact-, $n=14$ wells \\
\hline Day-7.5 blastocysts** & $109 / 205(53.2 \%)^{\mathrm{a}}$ & $147 / 225(65.3 \%)^{\mathrm{b}}$ & $134 / 210(63.8 \%)^{\mathrm{b}}$ \\
Expanded, hatching or hatched blastocysts*** & $50 / 109(45.9 \%)^{\mathrm{a}, \mathrm{Y}}$ & $88 / 147(59.9 \%)^{\mathrm{ab}, \mathrm{x}}$ & $88 / 134(65.7 \%)^{\mathrm{b}}$ \\
Total cell counts (mean \pm S.E.M.) & $111.08 \pm 6.07$ & $125.36 \pm 5.16$ & $117.86 \pm 5.75$ \\
ICM:TE ratio (mean \pm S.E.M.) & $0.36 \pm 0.031^{\mathrm{a}}$ & $0.47 \pm 0.027^{\mathrm{b}}$ & $0.36 \pm 0.029^{\mathrm{a}}$ \\
\hline
\end{tabular}

Within rows, values with different superscript letters differ significantly $(\mathrm{a}, \mathrm{b} ; \mathrm{P} \leq 0.05)$ or tend to differ $(\mathrm{X}, \mathrm{Y} ; \mathrm{P} \leq 0.1){ }^{* *}$ From cultured morulae; ***From total blastocysts.

compared to the Contact+ group. Contact- condition also increased the abundance of mRNA for BAX, an apoptosis-related gene, compared to Contact+ and Control Embryos groups (Fig. 3).

\section{Specificity of bEEC-induced effects on embryo development}

In the second experiment, in vitro-derived day-5.5 morulae were cultured in SOF+5\% FBS medium (Control Embryos), or in SOF-based medium conditioned by bEEC (bEECcond), or by mice fibroblasts (FIBRcond). On day 7.5 p.f., the number of blastocysts was significantly greater in the bEECcond compared to the Control and FIBRcond conditions (Table 2). However, there was no effect of bEECcond condition on the proportion of blastocysts that reached or surpassed the expanded-stage.

\section{Embryo-induced effects on bEEC transcriptome}

RNA sequencing generated a total of approximately 14.6 million reads per sample. Reads were mapped to the

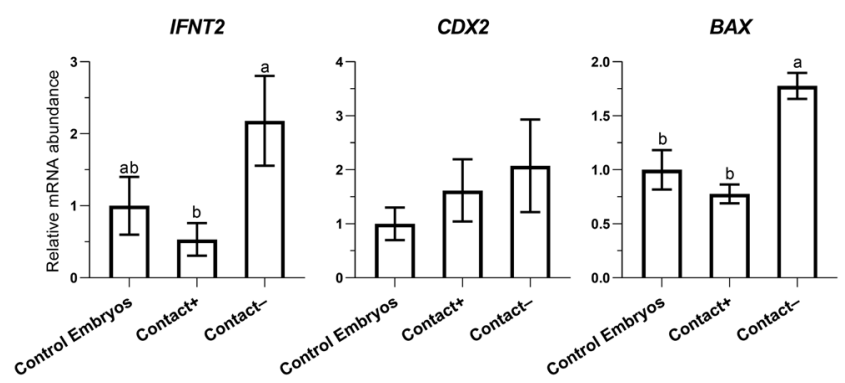

Figure 3 Juxtaposition to bEECs changes the abundance of specific transcripts in day-7.5 embryos. Relative mRNA abundance of interferon-tau (IFNT2), caudal type homeobox 2 (CDX2), and BCL2 associated $X$, apoptosis regulator $(B A X)$ on day 7.5 embryos cultured in SOF-based medium in the absence of bEEC (Control Embryos), juxtacrine (Contact+) or non-juxtacrine (Contact-) apposition. Each sample consists of a pool of 15 embryos from different culture wells of the same treatment group ( $n=4-5 /$ group). Data are shown as arbitrary units; mean \pm S.E.M. ${ }^{\text {a,b }}$ Statistically significant difference in mRNA abundance $(P \leq 0.05)$.
Bos taurus reference genome (assembly UMD3.1). After filtering, a total of 19,996 genes were used to identify DEGs (FDR $\leq$ 0.05). The data were deposited in Gene Expression Omnibus (GEO) under the accession number GSE151868. A total of 1797 (FDR $\leq 0.05$; Supplementary Dataset 1) genes were differentially expressed in the Contact+ group compared to their Control bEEC counterparts (Fig. 4). Only 230 DEGs (Supplementary Dataset 2), however, were found between Contact- and the Control bEEC group. Notably, from these 230 DEGs, a subset of 225 genes was found to be also differentially expressed in the Contact+ vs Control bEEC comparison. As denoted in Fig. 4, the 50 overlapping DEGs between Contact+ vs Control bEEC and Contact- vs Control bEEC comparisons likely represent the embryo-induced effects on bEEC transcriptome irrespective to juxtaposition. Interestingly, out of those 225 DEGs, 175 genes were also differentially expressed in the Contact+ vs Contactcomparison, indicating that juxtaposition of embryos to the bEEC monolayer also changed the magnitude of embryo-induced effects on bEEC transcriptome.

The comparison between Contact+ vs Contactyielded 899 (Supplementary Dataset 3) DEGs with 583 ( $65 \%$; Fig. 4) genes commonly changed in the Contact+ vs Control bEEC comparison plus 140 genes. The effect of embryo juxtaposition on endometrial transcriptome was accessed by this set of 723 DEGs that were exclusively changed when embryos were in contact with the bEEC monolayer (Fig. 4).

\section{Embryo-induced effects on bEEC transcriptome independent of juxtaposition}

These effects were assessed by the 50 overlapping DEGs retrieved in the Contact+ vs Control bEEC and Contact- vs Control bEEC comparisons. As shown in Fig. 5A, gene expression was modulated when compared to the Control group but similar between Contact+ and Contact-. The five most upregulated genes included interferon regulatory factor 9 (IRF9; 7.35-fold), sulfotransferase family 6B member 1 (SULT6B1; 6.46-fold), transmembrane protein 107 (TMEM107; -4.48-fold), TLH29 protein precursor-like (ISG12(B); 2.68-fold] and ring finger protein 31 (RNF31; 
Table 2 Specificity of bovine endometrial epithelial cells (bEEC)-driven effects on embryo development. On day 5.5 p.f. (post-fertilization), groups of $15 \pm 1$ untreated morulae were cultured in SOF-based medium (Control), in bEEC-conditioned medium (bEECcond), or in mice fibroblast-conditioned SOF medium (FIBRcond). Of the total oocytes (2320) assigned to in vitro fertilization, 821 (35.4\%) day-5.5 morulae were assigned to treatments. On day 7.5 p.f., embryonic developmental rates were recorded.

\begin{tabular}{lccc}
\hline \multirow{2}{*}{ Variables } & \multicolumn{3}{c}{ Groups } \\
\cline { 2 - 4 } Day 7.5 blastocysts** & Control, $n=21$ wells & bEECcond, $n=22$ & FIBRcond, $n=12$ \\
Expanded, hatching or hatched blastocysts*** & $178 / 315(56.5 \%)^{\mathrm{b}}$ & $234 / 328(71.3 \%)^{\mathrm{a}}$ & $100 / 178(56.2 \%)^{\mathrm{b}}$ \\
\hline
\end{tabular}

Within rows, values with different superscript letters differ significantly $(\mathrm{a}, \mathrm{b} ; P<0.001)$.

**From cultured morulae; ***From total blastocysts.

1.59-fold). IPA analysis of DEGs (FDR $\leq 0.05$; Cutoff fold-changes $>1.5$; Fig. 5B) identified canonical pathways related to Interferon Signaling and Role of PKR in Interferon Induction and Antiviral Response. In addition, pathways related to inflammatory responses (HMGB1 (inflammation high mobility group box 1 chromatinbinding protein) Signaling and IL-23 Signaling Pathway], and antigen presentation (Dendritic Cell Maturation) were retrieved. Other relevant pathways identified in the functional analysis include Prostanoid Biosynthesis and Stearate Biosynthesis.

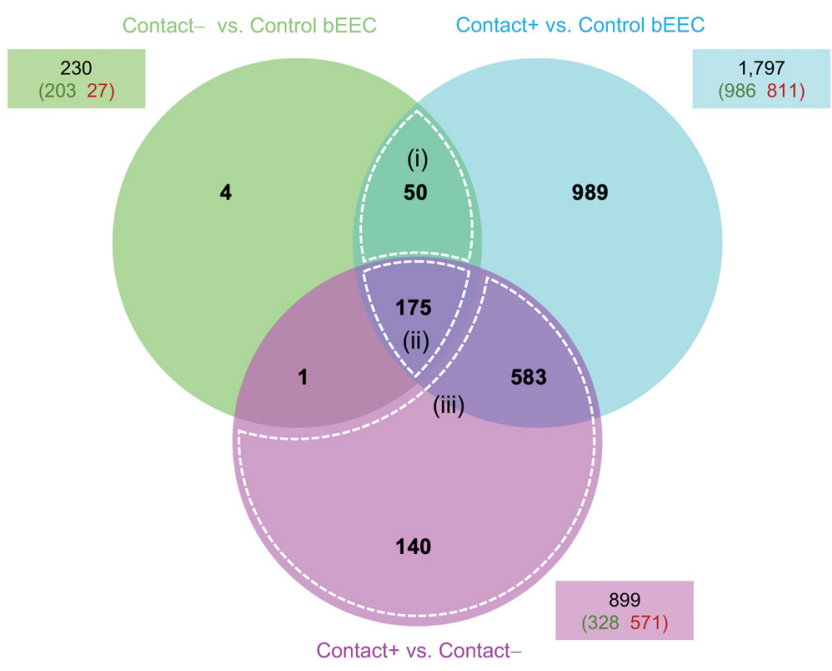

Figure 4 Embryo-induced effects on bEEC transcriptome. Venn diagram of RNAseq data from bovine endometrial epithelial cells (bEECs; $n=5$ / group) exposed to none (Control bEEC), in juxtaposition (Contact+) or non-juxtaposition (Contact-) to day-5.5 morulae for $48 \mathrm{~h}$.

Differentially expressed genes (DEGs) were selected using adjusted $P$ values (FDR $\leq 0.05)$. The number of up and downregulated genes are shown in green and red, respectively. (i) Embryo-induced effects regardless of juxtaposition are represented by the overlapping 50 DEGs yielded in the Contact+ vs Control bEEC, and Contact- vs Control bEEC comparisons. (ii) The set of 175 DEGs returned by all three comparisons represents genes whose magnitude of changes depended upon juxtaposition. (iii) Specific effects of embryo juxtaposition on bEEC transcriptome are represented by the remaining 723 DEGs yielded in the Contact+ vs Contact- comparison. See Supplemental Dataset S4 for a complete list of DEGs.

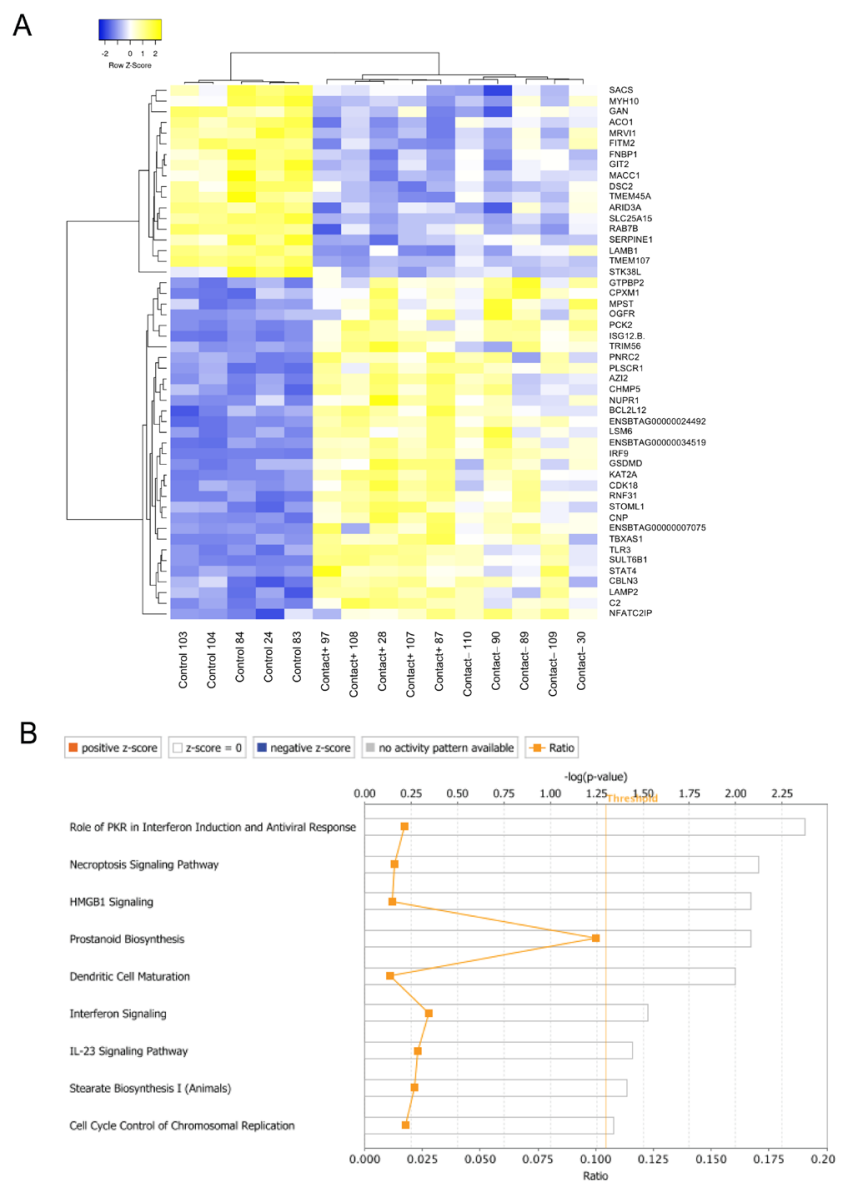

Figure 5 Embryo-induced effects on bEEC transcriptome regardless of juxtaposition. (A) Heatmap depicting the 50 differentially expressed genes (DEGs; FDR $\leq 0.05$ ) that represent embryo-induced effects on bEECs but that were not affected by juxtaposition. Reads were normalized within rows. Samples and genes were clustered by average linkage and Spearman rank correlation distances. (B) Overview of canonical pathways returned by Ingenuity Pathway Analysis (IPA) analysis of DEGs. Contact+ vs Control bEEC fold-changes (Cutoff $>1.5$ ) were considered in this analysis. The charts (y-axis) represent the top significantly enriched canonical pathways. The upper $x$-axis shows the $-\log$ of the value calculated based on Fisher's exact test. The ratio (bottom $\mathrm{x}$-axis) represented by the orange points is calculated based on the numbers of genes in a given pathway divided by the number of genes pertaining to that pathway. Straight orange vertical line represents the threshold for significance (by default). Canonical pathways shown were selected based on their biological significance (a detailed list of canonical pathways and genes involved in each pathway is provided in Supplementary Dataset 5). 


\section{Embryo-induced effects on bEEC transcriptome dependent on juxtaposition}

Venn diagram analysis allowed us to discriminate the set of genes whose magnitude of expression was modulated between Contact+ vs Contact- conditions (175 DEGs; Fig. 4) from genes that were regulated exclusively by Contact+ compared to the Contact- and Control bEEC groups (723 DEGs; Fig. 4). As demonstrated in Fig. 6A, Contactembryos elicited same direction (up- or down-regulation) but less pronounced changes on the 175 DEGs compared to the Contact+ condition. These 175 genes that represent changes in the magnitude of embryo-induced effects on bEEC transcriptome caused by juxtaposition include guanylate binding protein 4 (GBP4), interferon-induced protein 44 (IFI44), ATPase phospholipid transporting 8B4 (ATP8B4), Z-DNA binding protein 1 (ZBP1) and receptor transporter protein 4 (RTP4). IPA core analysis revealed an upregulation in interferon signaling-related canonical pathways (Interferon Signaling, Activation of IRF by Cytosolic Pattern Recognition Receptors, and Role of PKR in Interferon induction and Antiviral Response) in Contact+ compared to Contact- bEECs (Fig. 6B). Interestingly, the functional analysis also yielded pathways associated with antigen presentation in association with the major histocompatibility complex (MHC) system (i.e. Antigen Presentation Pathway and Allograft Rejection Signaling). Of note, allograft rejection is triggered by allorecognition when the host immune system detects same-species, nonself antigens.

A total of 723 genes had their expression modulated exclusively when embryos were juxtapositioned to bEECs (Contact+) but not by the Contact- condition, as shown in Fig. 7A. The top-5 DEGs include kinesin family member 5C (KIF5C), MX dynamin like GTPase 2 (MX2), IQ motif containing GTPase activating protein 3 (IQGAP3), ubiquitin-specific peptidase 25 (USP25) and cytoskeleton-associated protein 2 like (CKAP2L). IPA analysis identified enriched biological processes associated with cell cycle regulators, as for example Mitotic Roles of Polo-Like Kinase (upregulated), Cell Cycle: G2/M DNA Damage Checkpoint Regulation (downregulated), Cyclins and Cell Cycle Regulation (upregulated), and Cell Cycle Control of Chromosomal Replication (upregulated). Oxidative Phosphorylation, Estrogen-mediated S-phase Entry, and Pregnenolone Biosynthesis pathways were also retrieved by functional analysis of DEGs. An overview of canonical pathways impacted by juxtaposition between embryos and bEECs is provided in Fig. 7B.

\section{Ingenuity upstream regulator analysis}

To gain insights on the possible molecules triggering the transcriptome differences observed among the three conditions, upstream regulator analyses of DEGs $($ FDR $\leq 0.05$, Cutoff fold-changes $>1.5$ ) were performed

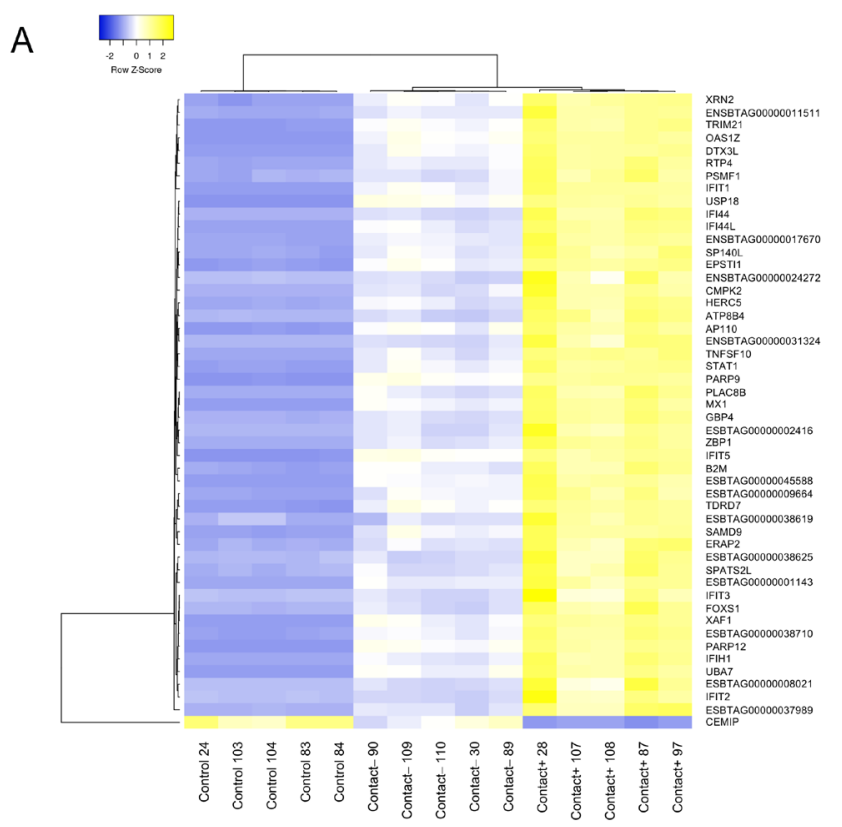

B

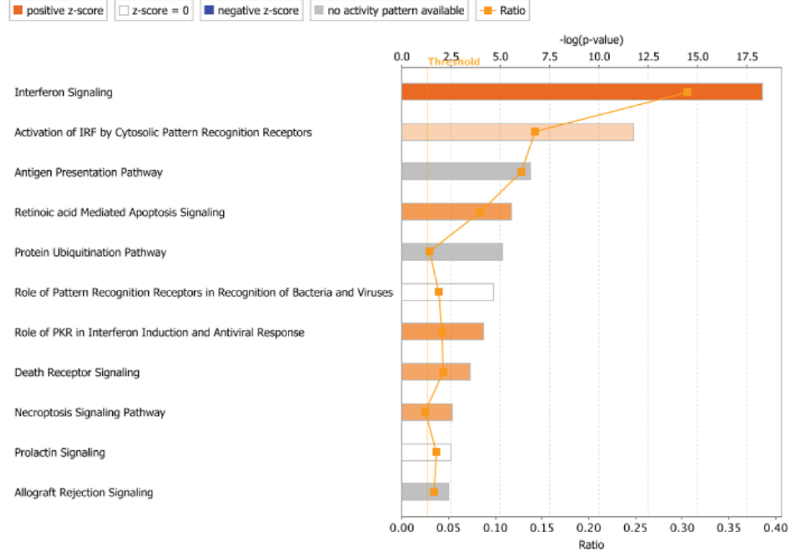

Figure 6 Juxtaposition changes magnitude of embryo-induced effects on bEEC transcriptome. (A) Heatmap depicting the top-50 differentially expressed genes (DEGs; FDR $\leq 0.05$ ) from a set of 175 genes that represent changes in magnitude of embryo-induced effects on bEEC transcriptome caused by juxtaposition. Reads were normalized within rows. Samples and genes were clustered by average linkage and Spearman rank correlation distances. (B) Overview of canonical pathways returned by Ingenuity Pathway Analysis (IPA) analysis. Contact+ vs Contact- fold-changes (Cutoff $>1.5$ ) were considered in this analysis. The charts ( $y$-axis) represent the top significantly enriched canonical pathways. The upper $\mathrm{x}$-axis shows the $-\log$ of the value calculated based on Fisher's exact test. The ratio (bottom $x$-axis) represented by the orange points is calculated based on the numbers of genes in a given pathway divided by the number of genes pertaining to that pathway. Straight orange vertical line represents the threshold for significance (by default). Canonical pathways shown were selected based on their biological significance (a detailed list of canonical pathways and genes involved in each pathway is provided in Supplementary Dataset 6).

in IPA software. A summary of upstream regulators among subsets of DEGs is provided in Table 3 (for a complete list please see Supplementary Dataset 8). Potential upstream regulators based on the 50 DEGs 
A

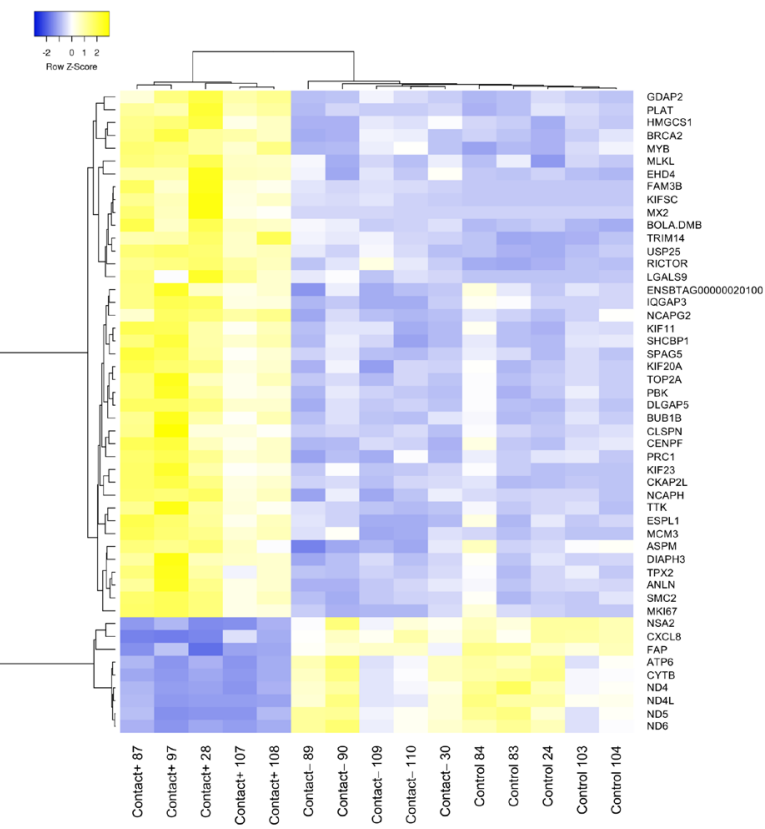

B

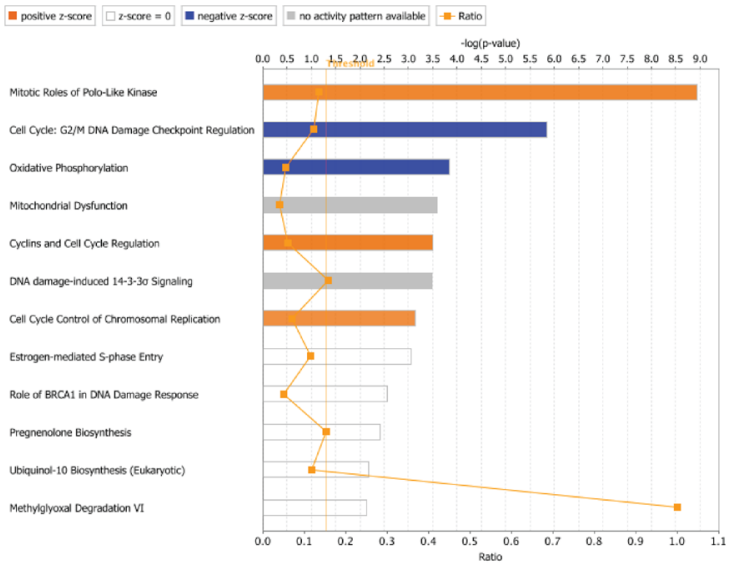

Figure 7 Juxtaposition changes nature of embryo-induced effects on bEEC transcriptome. (A) Heatmap depicting the top 50 differentially expressed genes (DEGs; FDR $\leq 0.05$ ) from a set of 723 genes whose expression was modulated exclusively when embryos were juxtapositioned to bEECs (Contact+) but not by the Contactcondition. Reads were normalized within rows. Samples and genes were clustered by average linkage and Spearman rank correlation distances. (B) Overview of canonical pathways returned by Ingenuity Pathway Analysis (IPA) analysis. Contact+ vs Contact- fold-changes (Cutoff $>1.5$ ) were considered in this analysis. The charts ( $y$-axis) represent the top significantly enriched canonical pathways. The upper $\mathrm{x}$-axis shows the -log of the value calculated based on Fisher's exact test. The ratio (bottom $\mathrm{x}$-axis) represented by the orange points is calculated based on the numbers of genes in a given pathway divided by the number of genes pertaining to that pathway. Straight orange vertical line represents the threshold for significance (by default). Canonical pathways shown were selected based on their biological significance (a detailed list of canonical pathways and genes involved in each pathway is provided in Supplementary Dataset 7). yielded in the Contact+ and Contact- vs Control bEECs confirmed type I interferon-signaling as an important upstream regulator triggering transcriptome changes in bEECs that were cultivated in the presence of embryos, regardless of juxtaposition. In addition, IL6 appears to be an important regulator of embryo-mediated effects on endometrial cells.

Upstream regulators predicted from the subset of 175 genes whose magnitude of expression was regulated between Contact+ and Contact- include Interferon alpha and the transcription regulator interferon regulatory factor 7 (IRF7). Analysis of the 723 genes differentially expressed exclusively when embryos were juxtapositioned to the bEEC monolayer retrieved zinc finger and BTB domain containing 17 (ZBTB17) and prostaglandin E receptor 2 (PTGER2) as potential upstream regulators. Intriguingly, medroxyprogesterone acetate also appeared as an upstream regulator of embryo-mediated effects of juxtaposition on bEEC transcriptome.

\section{Discussion}

The major players in pregnancy establishment are the embryo, the maternal reproductive tract and their reciprocal dialogue. Recent discoveries indicate that the endometrial transcriptome is locally changed by the presence of the embryo as early as day 7 in vivo in cattle (Sponchiado et al. 2017). Other in vitro studies showed that bovine embryos elicit responses in endometrial (Talukder et al. 2017, Gómez et al. 2018, Passaro et al. 2018), oviductal (García et al. 2017), luteal (Bridi et al. 2018) and immune (Talukder et al. 2018) cells. A critical question in this scenario is whether physical proximity of the embryo to the endometrium affects the magnitude of or is necessary for any changes in its transcriptome. Alternatively, embryo secretions could act on the surrounding cells in a classical paracrine manner. Using an exploratory approach based on a co-culture system, we interrogated the local embryo-endometrial interface for embryo-induced changes on endometrial cells transcriptome. Embryos were co-cultured in juxtacrine or non-juxtacrine apposition to bEECs for $48 \mathrm{~h}$ and the effects at the level of the embryo and the bEECs were investigated. We demonstrated that the bEEC supportive effects on embryo development do not depend on an embryo-bEECs juxtaposition. Nonetheless, our results revealed that the intensity and the characteristic of embryo-induced changes on endometrial epithelial cells transcriptome depend on a physical proximity between embryos and the bEEC monolayer.

We established an endometrial epithelial cell line in a manner that cells originating from the same pool were used in all replicates of each experiment. Even though the bEECs used here were at a low passage number 
Table 3 Top upstream regulators predicted based on differentially expressed genes (DEGs; FDR $\leq 0.05$, cutoff fold-changes $>1.5$ ) among the three conditions. Analysis was performed using IPA software.

\begin{tabular}{|c|c|c|c|c|}
\hline Upstream regulator & Molecule type & $\begin{array}{l}\text { Predicted } \\
\text { activation state }\end{array}$ & Activation z-score & $P$-value of overlap \\
\hline \multicolumn{5}{|c|}{ Embryo-induced effects on bEEC transcriptome independent of juxtaposition } \\
\hline IL6 & Cytokine & - & 1.507 & $3.72 \mathrm{E}-05$ \\
\hline IFNA2 & Cytokine & - & 1.927 & $4.87 \mathrm{E}-05$ \\
\hline ILIRN & Cytokine & - & - & $1.80 \mathrm{E}-04$ \\
\hline MAPK1 & Kinase & - & - & $2.93 \mathrm{E}-04$ \\
\hline 9(S)-HODE & Chemical/Endogenous & - & - & $8.61 \mathrm{E}-04$ \\
\hline \multicolumn{5}{|c|}{ Embryo-induced effects on bEEC transcriptome dependent of juxtaposition - changes in magnitude } \\
\hline IRF7 & Transcription regulator & Activated & 6.085 & $8.49 \mathrm{E}-61$ \\
\hline Interferon alpha & Group & Activated & 5.965 & $8.96 \mathrm{E}-59$ \\
\hline$N K X 2-3$ & Transcription regulator & Inhibited & -5.385 & $3.73 \mathrm{E}-37$ \\
\hline$P R L$ & Cytokine & Activated & 5.458 & $1.61 \mathrm{E}-35$ \\
\hline TRIM24 & Transcription regulator & Inhibited & -4.728 & $2.56 \mathrm{E}-34$ \\
\hline \multicolumn{5}{|c|}{ Embryo-induced effects on bEEC transcriptome dependent of juxtaposition - changes in nature } \\
\hline ZBTB17 & Transcription regulator & - & & $1.63 \mathrm{E}-47$ \\
\hline PTGER2 & G-protein coupled receptor & Activated & 5.375 & $2.52 \mathrm{E}-38$ \\
\hline CDKN1A & Kinase & Inhibited & -3.042 & $1.26 \mathrm{E}-30$ \\
\hline $\begin{array}{l}\text { Medroxyprogesterone } \\
\text { acetate }\end{array}$ & Chemical drug & Inhibited & -4.150 & $4.15 \mathrm{E}-19$ \\
\hline IL6 & Cytokine & - & 0.437 & $2.03 \mathrm{E}-10$ \\
\hline
\end{tabular}

(i.e. three passages), they co-expressed cytokeratin and vimentin as previously reported (Wang et al. 2000, Zeiler et al. 2007, Li et al. 2016) via a process described as epithelial-mesenchymal transition (Kalluri \& Weinberg 2009). At the third passage, the bEECs displayed a stable expression of markers of epithelial-cell origin (KRT18) and endometrial function (ESR1, IFNAR1 and PTGS2), which are representative of the expected in vivo phenotype.

Co-culture with bEECs stimulated embryo development from morula to blastocyst stage regardless of juxtaposition. In the present study, morulae were exposed to bEEC monolayers on day 5.5 p.f. to mimic the timing of the bovine embryo's arrival into the uterus in vivo (Guillomot 1994). Although the specific mechanisms by which endometrial cells influence early embryo development remain to be elucidated, many studies report that embryos at early developmental stages benefit from co-culture with endometrial cells in several species, including bovine (Voelkel et al. 1985), human (Rubio et al. 2000), mice (Kauma \& Matt 1995, Lai et al. 1996) and porcine (Allen \& Wright 1984).

Given that embryos-bEECs co-cultures and embryos (alone) cultures were conducted at $20 \% \mathrm{O}_{2}$, which is suboptimal for early embryo development, there is also a possibility that the cell monolayer could reduce the $\mathrm{O}_{2}$ tension of the embryo microenvironment in culture and, therefore, benefit the embryos in a non-specific manner (Nagao et al. 1994). In our second experiment, we eliminated the suggested importance of a reduced $\mathrm{O}_{2}$ tension caused by a feeder cell monolayer on embryo development by using a conditioned medium. We showed that medium conditioned by bEECs increased the proportion of morulae reaching the blastocyst stage compared to the Control group, similar to what was observed in the first experiment. Yet, the cell-specificity of the embryo supportive capacity of bEECs can be questioned by the fact that numerous investigations have demonstrated an improvement in development when embryos were co-cultured with non-endometrial homologous somatic cells, such as oviductal (Eyestone 1987, Thibodeaux et al. 1992), luteal (Maruri et al. 2018), or granulosa (Freeman et al. 1995, Malekshah et al. 2006) cells, or even in co-culture systems with adipose tissue-derived mesenchymal stem cells (Miranda et al. 2016). It has been also shown that co-culture with heterologous somatic cells, as for example BRL (buffalo rat liver) and Vero (green monkey kidney epithelial) cells, efficiently improve the development of mouse, bovine and human embryos (Ouhibi et al. 1990, Reed et al. 1996, Menck et al. 1997, Duszewska et al. 2000, Kattal et al. 2008). Taken together, these findings may suggest that the supportive role of bovine endometrial cells for embryo development in co-culture systems is non-specific. To test this, we challenged the specificity of the embryo supportive capacity of bEECs by using a medium conditioned by heterologous unspecific feeder cells. The mice fibroblast-conditioned medium had no effect on embryo development compared to the Control (SOF-based medium) condition. These observations suggest that bovine endometrial cells may provide a specific stimulus for continued development of early embryos in co-culture between days 5.5 and 7.5 after fertilization.

Although the beneficial role of co-culture on embryo development does not seem to be dependent on a juxtaposition with the bEEC monolayer, the embryo-bEEC contact did affect the cell commitment of the resulting 
blastocysts, as seen by the increased ICM:TE ratio in the Contact+ group. In mouse, it has been shown that cellto-cell interaction can influence the lineage specification of embryonic blastomeres (Lorthongpanich et al. 2012). The augmented ICM:TE ratio in Contact+ blastocysts, however, did not impact on transcript abundance of CDX2, a marker for trophectoderm cells. Additionally, day-7.5 blastocysts that were non-juxtapositioned to the bEEC monolayer displayed increased abundances of IFNT2 and $B A X$ mRNA compared to Contact+ embryos. It has been demonstrated that the attachment of trophectoderm to the uterine epithelium results in a decrease in IFNT expression during the implantation period in cattle (Ezashi \& Imakawa 2017). Also, Sakurai et al. (2012) reported that co-culture with endometrial epithelial cells resulted in decreased IFNT2 mRNA abundance in bovine trophoblast cells spheroids in vitro. The mechanisms by which the embryo-endometrium juxtaposition during the peri-hatching period could trigger different patterns in IFNT expression warrant further investigation.

By means of RNAseq, we obtained a genome-wide insight of the endometrial response to the presence of embryos. We verified a much stronger effect (1797 DEGs) elicited by the embryos when they were juxtapositioned to the bEEC monolayer. Transcriptome changes were rather limited between Contact- vs Control bEECs, with only 230 genes being differentially regulated. Analysis of the overlapping DEGs among the three comparisons allowed us to discriminate a subset of 50 genes whose expression was modulated in bEECs when exposed to embryos but independent of juxtaposition. Many of the upregulated DEGs were related to classical type I interferon-mediated pathways. In fact, functional analysis identified Interferon signaling as a major mediator to embryo-induced changes on bEEC transcriptome independent of juxtaposition. Blastocyst-induced changes in the abundance of Interferon-stimulated genes (ISGs) have been reported in the bovine endometrium in vivo (Sponchiado et al. 2017), in endometrial explants (Talukder et al. 2017, Passaro et al. 2018) and immune cells (Talukder et al. 2018) in vitro, and are likely triggered by IFNT produced by the embryo. Other studies later on pregnancy also reported major differences in the endometrial transcriptome between pregnant and cyclic cows being induced by IFNT (Bauersachs et al. 2006, Klein et al. 2006, Forde et al. 2011, Sánchez et al. 2019). There is no consensus about when the bovine embryo starts to produce IFNT. It has been shown that bovine blastocysts express and release IFNT into the culture medium (Hernandez-Ledezma et al. 1993). More recently, Talukder et al. (2018) reported the expression of IFNT at the protein level by bovine in vitro-produced morulae. Here, we demonstrated that in vitro-produced day-7.5 bovine embryos express transcripts for IFNT2, as well as that the bEECs used in our model express mRNA for interferon alpha and beta receptor subunit 1 (IFNAR1). Although IFNT has been extensively studied based on its ability to mediate pregnancy recognition in ruminants, its potential role in embryo development prior to the pregnancy recognition window is still not completely understood. For instance, it has been shown that the deletion of Isg15 results in 50\% pregnancy loss before placentation in mice (Ashley et al. 2010). However, a remaining open question is whether and to which extent classical ISGs have a biological role in programming the endometrium toward a more receptive and supportive status for the development of the bovine embryo in the context of early pregnancy (Pestka 2007).

The magnitude and nature of embryo-induced changes on endometrial transcriptome were largely dependent on juxtaposition between embryos and the bEEC monolayer. Our results identified 175 DEGs that represent changes in the magnitude of effects, whereas a set of 723 DEGs represents changes in nature of signaling triggered exclusively by Contact+ condition. Differences in magnitude of embryo-induced effects on bEEC transcriptome due to a juxtaposition between the embryos and the endometrial cells might be attributed to a diffusion gradient of embryo-derived signals when embryos were placed on transwell inserts, similar to what is expected to occur in non-adjacent, paracrine signaling in vivo. The pore density $(<2 \%$ of the surface area; $8.0 \mu \mathrm{m}$ pore size) of the insert membrane might limit or at least slow down the diffusion of secreted signaling molecules between the upper (containing the embryos) and the basal (containing the bEEC monolayer) compartments of the culture well, leading to a less pronounced endometrial response to embryo-derived soluble factors, as for example IFNT. In this regard, our data showed an upregulation of ISGs in the Contact+ compared to the Contact- bEECs. Moreover, upstream regulator analysis of the 175 DEGs predicted Interferon alpha and the transcription regulator interferon regulatory factor 7 (IRF7) as potential candidates of factors depicting transcriptional changes triggered by the juxtapositioned embryos on bEECs (Table 3 ). In addition to Interferon-associated pathways, IPA analysis of the 175 DEGs yielded biological processes related to antigen presentation in association with the MHC system (i.e. Antigen Presentation Pathway and Allograft Rejection Signaling). The DEGs pertaining to these pathways, beta 2-microglobulin (B2M), histocompatibility 2, T region locus 24 (H2T24), major histocompatibility complex, class I, B (HLA-B), proteasome subunit beta 8 (PSMB8) and 9 (PSMB9), and transporter 1, ATP binding cassette subfamily $\mathrm{B}$ member (TAP1), were upregulated in the Contact+ condition. These results provide evidence for a local immune response due to juxtaposition of embryos. Of note, allograft rejection is triggered by allorecognition when the host immune system detects same-species, non-self antigens. It is tempting to speculate that the 
local endometrial MHC system might play an important role on immune recognition and tolerance of the semiallogeneic embryo within the uterine lumen (Koch \& Platt 2003).

Pronounced effects on bEEC transcriptome were verified exclusively when embryos were juxtapositioned to the cell monolayer. A subset of 723 DEGs was used to assess the effects triggered by physical proximity between embryos and the bEECs. IPA analysis showed an enrichment for cell cycle biological processes. Further in vivo studies are necessary to address whether the endometrial epithelium changes its proliferation rate and/or its cell morphology in response to the local contact with the embryo/conceptus. Interestingly, the upstream regulator analysis showed medroxyprogesterone acetate as a potential candidate of factors depicting transcriptional changes between Contact+ and ContactbEECs. Some of the 20 DEGs (ANLN, ASPM, BIRC5, BRIP1, CCNB1, CCNB2, CDK1,CENPF, CKS2, CXCL5, DEPDC1, DLGAP5, KIF11, NCAPG, NEK2, NUSAP1, $P B K, P G R, P R C 1, S P C 25)$ pertaining to the mechanistic network (101 genes) have been found to be regulated by progesterone in the uterus (Shimizu et al. 2010, Forde et al. 2012, Xin et al. 2018). Limitations of the present work are that our model was hormone-free and did not take into account the glandular epithelium, limiting the direct physiological translatability of this finding.

Relatively little work has been done on the mechanisms underpinning a possible juxtracrine communication at the embryo-maternal interface prior to zona-hatching in monotocous mammals. It is known, however, that there is no intimate contact (i.e. tissue adhesion) between the pre-implantation, non-invasive embryo and the lining endometrial epithelium in the cow (Bazer et al. 1991). It is noteworthy that in this study, at the end of the co-culture period (day 7.5 p.f.), most embryos ( 83\%) were still enclosed in the zona pellucida. Direct cell-tocell contact at the pre-hatching stage might be provided by membrane extensions through the zona pellucida (Allen \& Wright 1984) and trophectoderm projections (Gonzales et al. 1996). Furthermore, it has been described that the zona pellucida could also contribute with binding sites and local release of signaling molecules (i.e. growth factors and cytokines) toward the endometrial cells (Denker 2000, Herrler et al. 2002). Alternatively, the embryos can also release extracellular vesicles that have the potential to trigger endometrial transcriptome and immune responses independently of a cell-to-cell contact (Bridi et al. 2020).

Another possible explanation for the embryo-induced effects on Contact + bEECs, that were not directly triggered by physical contact, is that Contact+ embryos may have a distinct capacity to secrete signaling molecules, compared to Contact- embryos. In the present study, no difference was observed between embryos derived from Contact+ vs Contact- conditions in terms of blastocyst development on day 7.5 p.f. However, the embryobEECs juxtaposition did impact the resulting blastocysts' cell commitment as seen by increased ICM:TE ratio in the Contact+ group, as well as on the 4 -fold greater abundance of transcripts for IFNT2 in the Contactembryos compared to their Contact+ counterparts. Thus, it is also reasonable to expect that the co-culture conditions affected the signaling capacity of those embryos. Although our experimental set-up does not allow us to distinguish between these possibilities, we speculate that differences on bEEC response to Contact+ vs Contact- embryos likely reflect a combination of the aforementioned mechanisms.

The present study provides new insights into the complex embryo-maternal interaction during the very early steps of pregnancy in cattle. On the embryonic side, the co-culture system applied in this study improved bovine embryonic development from morula to blastocyst stage. This support seems to be bEEC specific and does not rely on a juxtaposition between the embryo and the bEEC monolayer. Nonetheless, juxtaposition with bEECs altered day 7.5 blastocysts' cell fate and IFNT2 transcripts abundance. We demonstrated for the first time that peri-hatching bovine embryos drastically change the endometrial epithelial cell transcriptome. Highlighted pathways modulated by the presence of embryos included Interferon signaling and prostanoid biosynthesis. Moreover, our data reveal that nature and magnitude of embryo-induced effects are largely influenced by physical proximity between endometrial cells and embryos, with emphasis to antigen presentation and MHC systemassociated biological processes triggered in response to the semi-allogeneic embryos' presence. The functional consequences of this local recognition by the lining endometrial epithelium and how the embryo evades immune rejection in the bovine species, warrant further investigation.

\section{Supplementary materials}

This is linked to the online version of the paper at https://doi. org/10.1530/REP-20-0344.

\section{Declaration of interest}

The authors declare that there is no conflict of interest that could be perceived as prejudicing the impartiality of the research reported.

\section{Funding}

This work was supported by the Special Research Fund University of Antwerp (Joint-PhD Program, BOF-UA), and by the Coordenação de Aperfeiçoamento de Pessoal de Nível Superior - Brazil (CAPES; Finance Code 88881.132730/2016-01 to M S). 


\section{Data availability}

RNA sequencing data are available under accession number GSE151868.

\section{Author contribution statement}

M S, M B and J L M R L conceived the study. M S drafted the manuscript. M S, W F A M and G T S B performed experiments and analyzed data. P E J B critically revised the manuscript. $M$ B and J L M R L supervised the experiments. All authors edited and reviewed the manuscript.

\section{Acknowledgements}

The outstanding technical assistance of Gamete Research Centre staff and students to generate the embryos is gratefully acknowledged. The authors acknowledge Jens Slootmans for the assistance in performing RNA isolation and PCR analysis.

\section{References}

Allen RL \& Wright Jr RW 1984 In vitro development of porcine embryos in coculture with endometrial cell monolayers or culture supernatants. Journal of Animal Science 59 1657-1661. (https://doi.org/10.2527/ jas1984.5961657x)

Ashley RL, Henkes LE, Bouma GJ, Pru JK \& Hansen TR 2010 Deletion of the Isg15 gene results in up-regulation of decidual cell survival genes and down-regulation of adhesion genes: implication for regulation by IL-1 $\beta$. Endocrinology 151 4527-4536. (https://doi.org/10.1210/en.2010-0166)

Bauersachs S, Ulbrich SE, Gross K, Schmidt SEM, Meyer HHD, Wenigerkind H, Vermehren M, Sinowatz F, Blum H \& Wolf E 2006 Embryo-induced transcriptome changes in bovine endometrium reveal species-specific and common molecular markers of uterine receptivity. Reproduction 132 319-331. (https://doi.org/10.1530/rep.1.00996)

Bauersachs S, Ulbrich SE, Zakhartchenko V, Minten M, Reichenbach M, Reichenbach HD, Blum H, Spencer TE \& Wolf E 2009 The endometrium responds differently to cloned versus fertilized embryos. PNAS 106 5681-5686. (https://doi.org/10.1073/pnas.0811841106)

Bazer FW, Thatcher WW, Hansen PJ, Mirando MA, Ott TL \& Plante C 1991 Physiological mechanisms of pregnancy recognition in ruminants. Journal of Reproduction and Fertility: Supplement 43 39-47. (https://doi. org/10.1530/biosciprocs.2.004)

Bazer FW, Spencer TE \& Ott TL 1997 Interferon tau: a novel pregnancy recognition signal. American Journal of Reproductive Immunology 37 412-420. (https://doi.org/10.1111/j.1600-0897.1997.tb00253.x)

Brandao DO, Maddox-Hyttel P, Løvendahl P, Rumpf R, Stringfellow D \& Callesen H 2004 Post hatching development: a novel system for extended in vitro culture of bovine embryos. Biology of Reproduction 71 2048-2055. (https://doi.org/10.1095/biolreprod.103.025916)

Bridi A, Bertolin K, Rissi VB, Mujica LKS, Glanzner WG, De Macedo MPd, Comim FV, Gonçalves PBD \& Antoniazzi AQ 2018 Parthenogenetic bovine embryos secrete type I interferon capable of stimulating ISG15 in luteal cell culture. Animal Reproduction 15 1268-1277. (https://doi. org/10.21451/1984-3143-AR2018-0095)

Bridi A, Perecin F \& Silveira JCD 2020 Extracellular vesicles mediated early embryo-maternal interactions. International Journal of Molecular Sciences 21 1163. (https://doi.org/10.3390/ijms21031163)

Carter F, Forde N, Duffy P, Wade M, Fair T, Crowe MA, Evans ACO, Kenny DA, Roche JF \& Lonergan P 2008 Effect of increasing progesterone concentration from Day 3 of pregnancy on subsequent embryo survival and development in beef heifers. Reproduction, Fertility, and Development 20 368-375. (https://doi.org/10.1071/rd07204)

Denker HW 2000 Structural dynamics and function of early embryonic coats. Cells, Tissues, Organs 166 180-207. (https://doi. org/10.1159/000016732)
Diskin MG, Parr MH \& Morris DG 2011 Embryo death in cattle: an update. Reproduction, Fertility, and Development 24 244-251. (https://doi. org/10.1071/RD11914)

Diskin MG, Waters SM, Parr MH \& Kenny DA 2016 Pregnancy losses in cattle: potential for improvement. Reproduction, Fertility, and Development 28 83-93. (https://doi.org/10.1071/RD15366)

Duszewska AM, Reklewski Z, Pieńkowski M, Karasiewicz J \& Modliński JA 2000 Development of bovine embryos on Vero/BRL cell monolayers mixed co-culture. Theriogenology 54 1239-1247. (https://doi. org/10.1016/s0093-691x(00)00430-1)

Eyestone WH, Vignieri J \& First NL 1987 Coculture of early bovine embryos with oviducatl epithelium. Theriogenology 27 228. (https://doi. org/10.1016/0093-691X(87)90105-1)

Ezashi T \& Imakawa K 2017 Transcriptional control of IFNT expression. Reproduction 154 F21-F31. (https://doi.org/10.1530/REP-17-0330)

Forde N, Carter F, Fair T, Crowe MA, Evans ACO, Spencer TE, Bazer FW, Mcbride R, Boland MP, O'Gaora P et al. 2009 Progesterone-regulated changes in endometrial gene expression contribute to advanced conceptus development in cattle. Biology of Reproduction 81 784-794. (https://doi.org/10.1095/biolreprod.108.074336)

Forde N, Carter F, Spencer TE, Bazer FW, Sandra O, Mansouri-Attia N, Okumu LA, Mcgettigan PA, Mehta JP, Mcbride R et al. 2011 Conceptusinduced changes in the endometrial transcriptome: how soon does the cow know she is pregnant? Biology of Reproduction 85 144-156. (https://doi.org/10.1095/biolreprod.110.090019)

Forde N, Mehta JP, Minten M, Crowe MA, Roche JF, Spencer TE \& Lonergan P 2012 Effects of low progesterone on the endometrial transcriptome in cattle. Biology of Reproduction 87 124. (https://doi. org/10.1095/biolreprod.112.103424)

Freeman MR, Whitworth CM \& Hill GA 1995 Granulosa cell co-culture enhances human embryo development and pregnancy rate following in-vitro fertilization. Human Reproduction 10 408-414. (https://doi. org/10.1093/oxfordjournals.humrep.a135953)

García EV, Hamdi M, Barrera AD, Sánchez-Calabuig MJ, GutiérrezAdán A \& Rizos D 2017 Bovine embryo-oviduct interaction in vitro reveals an early cross talk mediated by BMP signaling. Reproduction 153 631-643. (https://doi.org/10.1530/REP-16-0654)

Gómez E, Sánchez-Calabuig MJ, Martin D, Carrocera S, Murillo A, Correia-Alvarez E, Herrero $P$, Canela N, Gutiérrez-Adán A, Ulbrich S et al. 2018 In vitro cultured bovine endometrial cells recognize embryonic sex. Theriogenology 108 176-184. (https://doi.org/10.1016/j. theriogenology.2017.11.038)

Gonzales DS, Jones JM, Pinyopummintr T, Carnevale EM, Ginther OJ, Shapiro SS \& Bavister BD 1996 Implantation: trophectoderm projections: a potential means for locomotion attachment and implantation of bovine equine and human blastocysts. Human Reproduction 11 2739-2745. (https://doi.org/10.1093/oxfordjournals.humrep.a019201)

Guillomot M 1995 Cellular interactions during implantation in domestic ruminants. Journal of Reproduction and Fertility: Supplement 49 39-51.

Hernandez-Ledezma J, Mathialagan N, Villanueva C, Sikes JD \& Roberts RM 1993 Expression of bovine trophoblast interferons by in vitro-derived blastocysts is correlated with their morphological quality and stage of development. Molecular Reproduction and Development 36 1-6. (https://doi.org/10.1002/mrd.1080360102)

Herrler A, Von Wolff M \& Beier HM 2002 Proteins in the extraembryonic matrix of preimplantation rabbit embryos. Anatomy and Embryology 206 49-55. (https://doi.org/10.1007/s00429-002-0270-9)

Ireland JJ, Murphee RL \& Coulson PB 1980 Accuracy of predicting stages of bovine estrous cycle by gross appearance of the corpus luteum. Journal of Dairy Science 63 155-160. (https://doi.org/10.3168/jds. S0022-0302(80)82901-8)

Kalluri R \& Weinberg RA 2009 The basics of epithelial-mesenchymal transition. Journal of Clinical Investigation 119 1420-1428. (https://doi. org/10.1172/JCl39104)

Kattal N, Cohen J \& Barmat LI 2008 Role of coculture in human in vitro fertilization: a meta-analysis. Fertility and Sterility 90 1069-1076. (https://doi.org/10.1016/j.fertnstert.2007.07.1349)

Kauma SW \& Matt DW 1995 Coculture cells that express leukemia inhibitory factor LIF enhance mouse blastocyst developmentin vitro. Journal of Assisted Reproduction and Genetics 12 153-156. (https://doi. org/10.1007/BF02211386) 
Klein C, Bauersachs S, Ulbrich SE, Einspanier R, Meyer HHD, Schmidt SEM, Reichenbach HD, Vermehren M, Sinowatz F, Blum H et al. 2006 Monozygotic twin model reveals novel embryo-induced transcriptome changes of bovine endometrium in the preattachment period. Biology of Reproduction 74 253-264. (https://doi.org/10.1095/ biolreprod.105.046748)

Koch CA \& Platt JL 2003 Natural mechanisms for evading graft rejection: the fetus as an allograft. Springer Seminars in Immunopathology 25 95-117. (https://doi.org/10.1007/s00281-003-0136-0)

Lai YM, Wang HS, Lee CL, Lee JD, Huang HY, Chang FH, Lee JF \& Soong YK 1996 Insulin-like growth factor-binding proteins produced by Vero cells human oviductal cells and human endometrial cells and the role of insulin-like growth factor-binding protein-3 in mouse embryo co-culture systems. Human Reproduction 11 1281-1286. (https://doi. org/10.1093/oxfordjournals.humrep.a019372)

Li X, Li Z, Hou D, Zhao Y, Wang C \& Li X 2016 The bovine endometrial epithelial cells promote the differentiation of trophoblast stem-like cells to binucleate trophoblast cells. Cytotechnology 68 2687-2698. (https:// doi.org/10.1007/s10616-016-9994-x)

Lorthongpanich C, Doris TPY, Limviphuvadh V, Knowles BB \& Solter D 2012 Developmental fate and lineage commitment of singled mouse blastomeres. Development 139 3722-3731. (https://doi.org/10.1242/ dev.086454)

Macklon NS \& Brosens JJ 2014 The human endometrium as a sensor of embryo quality. Biology of Reproduction 91 98. (https://doi.org/10.1095/ biolreprod.114.122846)

Malekshah AK, Moghaddam AE \& Daraka SM 2006 Comparison of conditioned medium and direct co-culture of human granulosa cells on mouse embryo development. Indian Journal of Experimental Biology 44 189-192.

Mansouri-Attia N, Sandra O, Aubert J, Degrelle S, Everts RE, GiraudDelville C, Heyman Y, Galio L, Hue I, Yang X et al. 2009 Endometrium as an early sensor of in vitro embryo manipulation technologies. PNAS 106 5687-5692. (https://doi.org/10.1073/pnas.0812722106)

Marei WFA, Van Raemdonck G, Baggerman G, Bols PEJ \& Leroy JLMR 2019 Proteomic changes in oocytes after in vitro maturation in lipotoxic conditions are different from those in cumulus cells. Scientific Reports $\mathbf{9}$ 3673. (https://doi.org/10.1038/s41598-019-40122-7)

Maruri A, Cruzans PR, Lorenzo MS, Tello MF, Teplitz GM, Carou MC \& Lombardo DM 2018 Embryotrophic effect of a short-term embryo coculture with bovine luteal cells. Theriogenology 119 143-149. (https://doi.org/10.1016/j.theriogenology.2018.06.032)

Menck MC, Guyader-Joly C, Peynot N, Le Bourhis D, Lobo RB, Renard JP \& Heyman Y 1997 Beneficial effects of Vero cells for developing IVF bovine eggs in two different coculture systems. Reproduction, Nutrition, Development 37 141-150. (https://doi.org/10.1051/rnd:19970202)

Mesquita FS, Ramos RS, Pugliesi G, Andrade SC, Van Hoeck V, Langbeen A, Oliveira ML, Gonella-Diaza AM, Gasparin G, Fukumasu H et al. 2015 The receptive endometrial transcriptomic signature indicates an earlier shift from proliferation to metabolism at early diestrus in the cow. Biology of Reproduction 92 52, 1-12. (https://doi.org/10.1095/ biolreprod.115.129031)

Miranda MS, Nascimento HS, Costa MPR, Costa NN, Brito KNL, Lopes CTA, Santos SSD, Cordeiro MS \& Ohashi OM 2016 Increasing of blastocyst rate and gene expression in co-culture of bovine embryos with adult adipose tissue-derived mesenchymal stem cells. Journal of Assisted Reproduction and Genetics 33 1395-1403. (https://doi.org/10.1007/ s10815-016-0779-0)

Nagao Y, Saeki K, Hoshi M \& Kainuma H 1994 Effects of oxygen concentration and oviductal epithelial tissue on the development of in vitro matured and fertilized bovine oocytes cultured in protein-free medium. Theriogenology 41 681-687. (https://doi.org/10.1016/0093691x(94)90177-k)

Ouhibi N, Hamidi J, Guillaud J \& Ménézo Y 1990 Co-culture of 1-cell mouse embryos on different cell supports. Human Reproduction 5 737-743. (https://doi.org/10.1093/oxfordjournals.humrep.a137178)

Passaro C, Tutt D, Mathew DJ, Sanchez JM, Browne JA, Boe-Hansen GB, Fair T \& Lonergan P 2018 Blastocyst-induced changes in the bovine endometrial transcriptome. Reproduction 156 219-229. (https://doi. org/10.1530/REP-18-0188)
Pestka S 2007 The interferons: 50 years after their discovery there is much more to learn. Journal of Biological Chemistry 282 20047-20051. (https://doi.org/10.1074/jbc.R700004200)

Pfaffl MW 2001 A new mathematical model for relative quantification in real-time RT-PCR. Nucleic Acids Research 29 e45-e45. (https://doi. org/10.1093/nar/29.9.e45)

Reed WA, Suh TK, Bunch TD \& White KL 1996 Culture of in vitro fertilized bovine embryos with bovine oviductal epithelial cells buffalo rat liver BRL cells or BRL-cell-conditioned medium. Theriogenology 45 439-449. (https://doi.org/10.1016/0093-691x(95)00380-q)

Rizos D, Clemente M, Bermejo-Alvarez P, de La Fuente J, Lonergan P \& Gutiérrez-Adán A 2008 Consequences of in vitro culture conditions on embryo development and quality. Reproduction in Domestic Animals 43 44-50. (https://doi.org/10.1111/j.1439-0531.2008.01230.x)

Rubio C, Simón C, Mercader A, Garcia-Velasco J, Remohí J \& Pellicer A 2000 Clinical experience employing co-culture of human embryos with autologous human endometrial epithelial cells. Human Reproduction 15 (Supplement 6) 31-38.

Sakurai T, Bai H, Bai R, Arai M, Iwazawa M, Zhang J, Konno T, Godkin JD, Okuda K \& Imakawa K 2012 Coculture system that mimics in vivo attachment processes in bovine trophoblast cells. Biology of Reproduction 87 60. (https://doi.org/10.1095/biolreprod.112.100180)

Sánchez JM, Mathew DJ, Behura SK, Passaro C, Charpigny G, Butler ST, Spencer TE \& Lonergan P 2019 Bovine endometrium responds differentially to age-matched short and long conceptuses. Biology of Reproduction 101 26-39. (https://doi.org/10.1093/biolre/ioz060)

Shimizu T, Krebs S, Bauersachs S, Blum H, Wolf E \& Miyamoto A 2010 Actions and interactions of progesterone and estrogen on transcriptome profiles of the bovine endometrium. Physiological Genomics 42A 290-300. (https://doi.org/10.1152/physiolgenomics.00107.2010)

Sponchiado M, Gomes NS, Fontes PK, Martins T, Del Collado M, De Assumpção Pastore AA, Pugliesi G, Nogueira MFG \& Binelli M 2017 Pre-hatching embryo-dependent and -independent programming of endometrial function in cattle. PLOS ONE 12 e0175954. (https://doi. org/10.1371/journal.pone.0175954)

Sponchiado M, Gonella-Diaza AM, Rocha CC, Turco EGL, Pugliesi G, Leroy JLMR \& Binelli M 2019 The pre-hatching bovine embryo transforms the uterine luminal metabolite composition in vivo. Scientific Reports 9 8354. (https://doi.org/10.1038/s41598-019-44590-9)

Talukder AK, Yousef MS, Rashid MB, Awai K, Acosta TJ, Shimizu T, Okuda K, Shimada M, Imakawa K \& Miyamoto A 2017 Bovine embryo induces an anti-inflammatory response in uterine epithelial cells and immune cells in vitro: possible involvement of interferon tau as an intermediator. Journal of Reproduction and Development 63 425-434. (https://doi.org/10.1262/jrd.2017-056)

Talukder AK, Rashid MB, Yousef MS, Kusama K, Shimizu T, Shimada M, Suarez SS, Imakawa K \& Miyamoto A 2018 Oviduct epithelium induces interferon-tau in bovine day-4 embryos which generates an anti-inflammatory response in immune cells. Scientific Reports $\mathbf{8} 7850$. (https://doi.org/10.1038/s41598-018-26224-8)

Thathiah A \& Carson DD 2002 Mucins and blastocyst attachment. Reviews in Endocrine and Metabolic Disorders 3 87-96. (https://doi. org/10.1023/a:1015446626671)

Thibodeaux JK, Myers MW, Goodeaux LL, Menezo Y, Roussel JD, Broussard JR \& Godke RA 1992 Evaluating an in vitro culture system of bovine uterine and oviduct epithelial cells for subsequent embryo coculture. Reproduction, Fertility, and Development 4 573-583. (https:// doi.org/10.1071/rd9920573)

Voelkel SA, Amborski GF, Hill KG \& Godke RA 1985 Use of a uterinecell monolayer culture system for micromanipulated bovine embryos. Theriogenology $24 \quad 271-281 . \quad$ (https://doi.org/10.1016/0093691x(85)90218-3)

Wang G, Johnson GA, Spencer TE \& Bazer FW 2000 Isolation, immortalization and initial characterization of uterine cell lines: an in vitro model system for the procine uterus. In Vitro Cellular and Developmental Biology: Animal 36 650-656. (doi:10.1290/10712690(2000)036<0650:iiaico>2.0.co;2)

Wolf E, Arnold GJ, Bauersachs S, Beier HM, Blum H, Einspanier R, Fröhlich T, Herrler A, Hiendleder S, Kölle S et al. 2003 Embryo-maternal communication in bovine-strategies for deciphering a complex 
cross-talk. Reproduction in Domestic Animals 38 276-289. (https://doi. org/10.1046/j.1439-0531.2003.00435.x)

Wydooghe E, Vandaele L, Beek J, Favoreel H, Heindryckx B, De Sutter P \& Van Soom A 2011 Differential apoptotic staining of mammalian blastocysts based on double immunofluorescent CDX2 and active caspase-3 staining. Analytical Biochemistry 416 228-230. (https://doi. org/10.1016/j.ab.2011.05.033)

Xin Q, Kong S, Yan J, Qiu J, He B, Zhou C, Ni Z, Bao H, Huang L, Lu J et al. 2018 Polycomb subunit BMI1 determines uterine progesterone responsiveness essential for normal embryo implantation. Journal of Clinical Investigation 128 175-189. (https://doi.org/10.1172/JCl92862)

Zeiler M, Leiser R, Johnson GA, Tinneberg HR \& Pfarrer C 2007 Development of an in vitro model for bovine placentation: a comparison of the in vivo and in vitro expression of integrins and components of extracellular matrix in bovine placental cells. Cells, Tissues, Organs $\mathbf{1 8 6}$ 229-242. (https://doi.org/10.1159/000107947)

Received 17 June 2020

First decision 20 July 2020

Revised Manuscript received 21 August 2020

Accepted 17 September 2020 